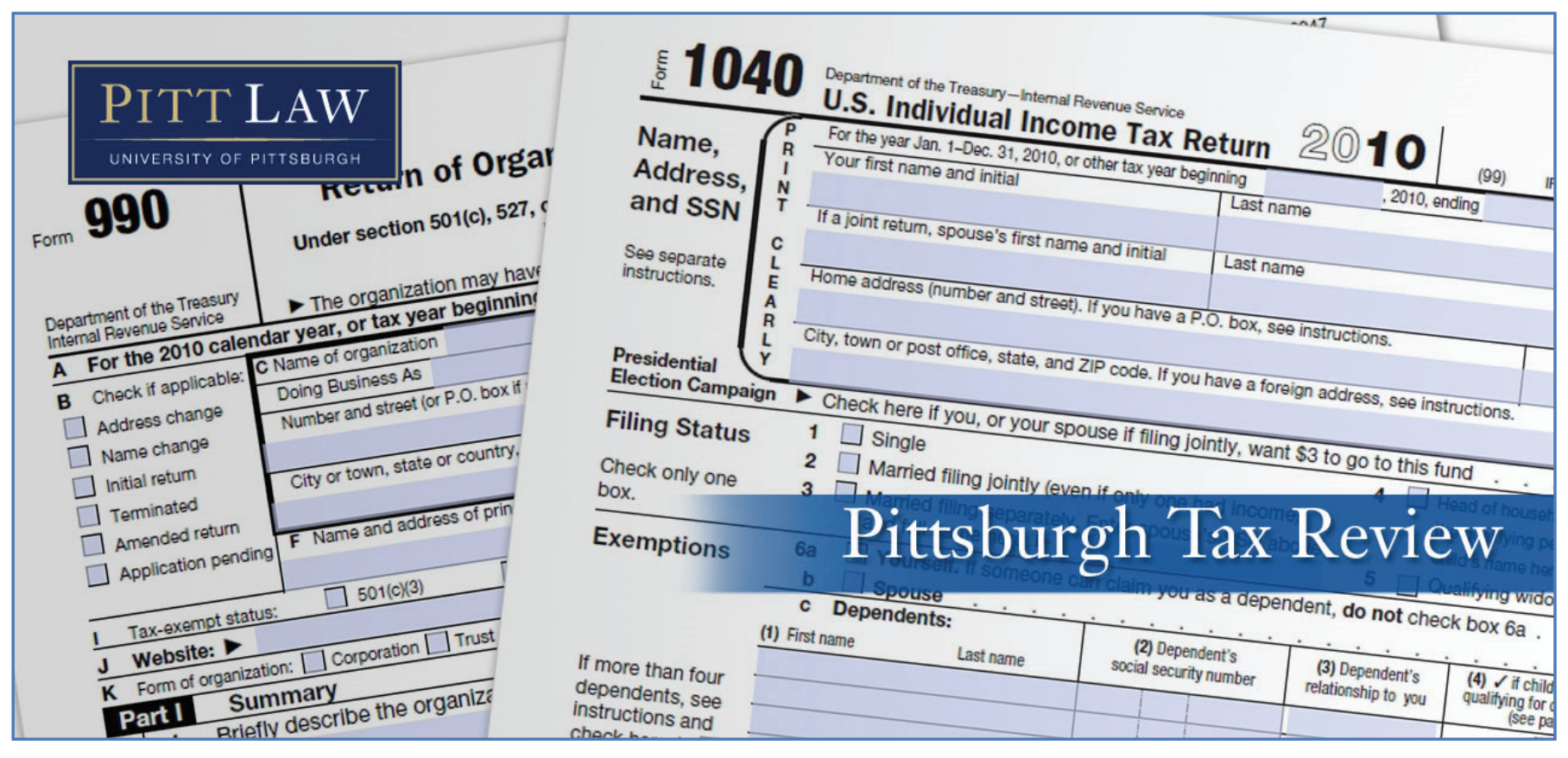

Volume 10 (2013) | ISSN 1932-1821 (print) 1932-1996 (online)

DOI 10.5195/taxreview.2013.16 | http://taxreview.law.pitt.edu

\title{
ENTRY-LEVEL ENTREPRENEURS AND THE CHOICE-OF-ENTITY CHALLENGE
}

\author{
Emily Ann Satterthwaite
}

\section{$(\mathrm{CC})$ BY-NC-ND}

This work is licensed under a Creative Commons Attribution-Noncommercial-No Derivative Works 3.0 United States License.

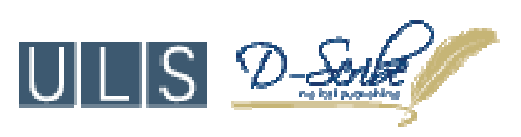

This journal is published by the University Library System of the University of Pittsburgh as part of its D-Scribe Digital Publishing Program, and is cosponsored by the University of Pittsburgh Press. 


\title{
ENTRY-LEVEL ENTREPRENEURS AND THE CHOICE-OF-ENTITY CHALLENGE
}

\author{
Emily Ann Satterthwaite*
}

\begin{abstract}
For first-time, lower-income and credit-constrained entrepreneurs ("entry-level entrepreneurs"), the employment tax savings proffered by a longstanding tax shelter known as the "Sub-S Shelter" can be particularly salient. Such hypersalience is problematic from a policy perspective. It not only increases the costs and complexity of the entry-level entrepreneur's deliberation process concerning the appropriate entity for her business, but it distorts her incentives to choose the entity that best supports her business's future growth. I argue that because the hypersalience of the SubShelter is likely to be more pronounced for entry-level entrepreneurs than for entrepreneurs with more experience or better access to capital, the burdens of the shelter are distributionally regressive. As an alternative to full-scale reforms that would eliminate the demand for the Sub-S Shelter but may be politically infeasible, I suggest that the shelter's regressive hypersalience can be addressed by government measures to provide choiceof-entity information tailored to the needs and concerns of entry-level entrepreneurs. Such targeted information can mitigate the hypersalience of the Sub-S Shelter by underscoring the risks of relying on it, while highlighting the real option value of choosing a more flexible business entity such as an LLC. By nudging entry-level entrepreneurs towards neutrality in regard to their choice-of-entity decisions, this approach has the potential to improve both the efficiency and the equity of a key step in formalizing a new business.

\footnotetext{
* University of Toronto Faculty of Law. The author is grateful to Mirit Eyal-Cohen, Elizabeth Kregor, Leandra Lederman, Paul Tremblay, participants at the 2012 Critical Tax Theory Workshop and participants at the 2008 New York University Clinical Writers' Workshop for valuable comments and suggestions. I am also indebted to my former clients at the Institute for Justice Clinic on Entrepreneurship and my former colleagues at the University of Chicago Law School for feedback, guidance and inspiration at the very beginning of this project.
}

Pitt Tax Review | ISSN 1932-1821 (print) 1932-1996 (online)

DOI 10.5195/taxreview.2013.16 | http://taxreview.law.pitt.edu 


\section{0 | Pittsburgh Tax Review | Vol. 102013}

Table of Contents

Introduction

I. Entrepreneurs' Choice-of-Entity Problem in a Nutshell: With and Without the Sub-S Shelter...

A. Choice-of Entity in a World Without the Sub-S Shelter 152

1. Is a Separate Entity Necessary?.

2. What Are the Primary Separate-Entity Options for Entry-Level Entrepreneurs?

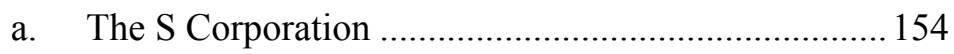

b. The LLC .................................................................. 156

3. The Case Against the S Corporation ................................ 157

a. Limitation on Shareholders May Shut Out

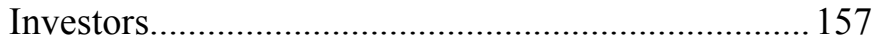

b. One Class of Stock Limits Growth ............................ 158

c. Conversion Has Negative Tax Consequences ........... 161

4. The Case for the LLC ......................................................... 162

a. Maximize Liability Protection Under State Law ....... 162

b. Tax Attributes of an LLC ............................................... 164

i. Improve Basis Treatment Affecting a Future Potential Sale ….............................................. 164

ii. Pass-Through of Losses .................................... 166

iii. Allow Easy Conversion to a Different Type of Entity ............................................................. 167

5. Conclusion: S Corporation Versus LLC............................ 168

B. Employment Taxes and the Operation of the Sub-S Shelter..... 168

1. Employment Tax Basics................................................... 168

2. Employment Taxes in a Corporation: The Sub-S Shelter.

3. Employment Taxes in an LLC 
4. Are There Any Sub-S Shelter "Workarounds" Available to LLCs?.

II. The Regressive Hypersalience of the Sub-S Shelter and Its Impacts

A. The Sub-S Shelter Is Hypersalient for Entry-Level

Entrepreneurs

1. Entry-Level Entrepreneurs Have Lower Expected Earnings

2. Entry-Level Entrepreneurs Have High Personal Discount Rates 180

3. Entry-Level Entrepreneurs Are Over-Optimistic

4. The Structure of the Sub-S Shelter Interacts with Characteristics Typical of Entry-Level Entrepreneurs to Make Its Benefits Hypersalient.

B. The Hypersalience of the Sub-S Shelter Has Regressive Equity Implications

1. The Sub-S Shelter Increases Complexity for EntryLevel Entrepreneurs as Compared to Other Entrepreneurs.

2. The Sub-S Shelter "Call Option" Distorts the Entity Decision

III. Salience Manipulation in Favor of the LLC as a Route to Real Option Value

A. Choice-of-Entity as Real Option 194

B. Restructuring the Sub-S Shelter Call Option as a Real Option 196

IV. Conclusion 202

Pitt Tax Review | ISSN 1932-1821 (print) 1932-1996 (online) DOI 10.5195/taxreview.2013.16 | http://taxreview.law.pitt.edu 


\section{INTRODUCTION}

Entrepreneurship in the United States is often a countercyclical phenomenon: more new businesses get started during recessions than during periods of economic growth. ${ }^{1}$ Contrary to the stereotype of the entrepreneur as a deep-pocketed elite, many entrepreneurial ventures are launched in the shadow of unemployment. ${ }^{2}$ For the individuals starting such businesses, entrepreneurship may be bound up with notions of selfdetermination and the desire to pursue one's dreams, but first and foremost it is a response to economic necessity.

This Article presumes that policymakers should not overlook this demographic of first-time, lower-income and credit-constrained entrepreneurs ("entry-level entrepreneurs") when conceiving of public policies that seek to foster and support entrepreneurship in the United States. Accordingly, this Article identifies one existing policy that has attracted little attention in the tax and business law literature despite its centrality to the endeavor of formalizing a new business. I argue that the most basic legal step involved in starting up - the task of choosing the appropriate state-law limited liability business entity-places disproportionate burdens on entry-level entrepreneurs.

As a practical matter, the choice-of-entity maze confronts all entrepreneurs regardless of their sophistication or access to resources.

${ }^{1}$ See Robert W. Fairlie, Entrepreneurship, Economic Conditions, and the Great Recession, $22 \mathrm{~J}$. ECON. \& MGMT. StRATEGY 207 (finding that entrepreneurship increased as local labor market conditions worsened in the "Great Recession"). For an overview of the "recession push" theory of entrepreneurship, see Emilio Congregado et al., The Dynamics of Entrepreneurship: Hysteresis, Business Cycles and Government Policy, 43 EMPIRICAL ECON. 1239, 1243-44 (2012) (identifying low costs in recessions as an incentive to produce, noting that displacement of incumbents is more common in recessions (the "recession cleansing effect") and recognizing "the emergence of worker co-operatives and other 'marginal' enterprises in recessions, which dissolve in economic recoveries when conventional employment opportunities become more readily available.").

2 Fairlie, supra note 1, at 209-11, 227 ("These results indicate that the recent rise in entrepreneurship rates is primarily due to the rapidly weakening conditions in the labor market as measured by local unemployment rates.... Changes in local labor market conditions are the main determinant of changes in the entrepreneurship rate." Id. at 227.). See also David S. Evans \& Linda S. Leighton, Some Empirical Aspects of Entrepreneurship, 79 AM. ECON. REV. 3 519-35, 521 (1989) (finding in an analysis of male entrepreneurship in the early 1980s that "unemployed workers, lowerpaid wage workers, and men who have changed jobs a lot . . . are more likely to enter self-employment or to be self-employed at a point in time, all else equal.").

Pitt Tax Review | ISSN 1932-1821 (print) 1932-1996 (online)

DOI 10.5195/taxreview.2013.16 | http://taxreview.law.pitt.edu 
However, a loophole within the tax law that is generally perceived to benefit affluent professionals also can be used by closely-held businesses if they choose to be taxed under Subchapter S of the Internal Revenue Code (the "Code"). The loophole, colloquially referred to by some as the "Sub-S Shelter," has attracted varying degrees of condemnation for allowing income from services to be sheltered from the full reach of employment taxes when earned through a corporation that has elected to be taxable under Subchapter S (an "S Corporation"). ${ }^{4}$

Although the origins and contours of the employment tax rules that generate the Sub-S Shelter are well-understood, ${ }^{5}$ and while there is broad consensus that the shelter represents a substantial contributor to the federal tax gap, ${ }^{6}$ a key implication of its structure has been overlooked: for entrylevel entrepreneurs in particular, the potential employment tax savings yielded by the Sub-S Shelter are positioned to be highly salient, or "hypersalient." ${ }^{, 7}$ Salience, or the prominence or noticeability of a tax for a given

\footnotetext{
${ }^{3}$ The Sub-S Shelter is also known as the "John Edwards Shelter" after one of its best-known beneficiaries. The list of politicians and public figures who have allegedly used the shelter is long. For instance, during the 2012 presidential campaign, Newt Gingrich was in the news for using the shelter to reduce his employment tax liability. See Janet Novak, Gingrich Used Payroll Tax Ploy Often Attacked by IRS, FORBES, Jan. 22, 2012, http://www.forbes.com/sites/janetnovack/2012/01/22/ gingrich-usedpayroll-tax-ploy-often-attacked-by-irs/.

4 See, e.g., Liberal Loopholes, WALL ST. J., July 13, 2004, at A14, available at http://online.wsj.com/article/0,,SB108967570582861859,00.html. For discussion of John Edwards's use of the shelter, see Walter D. Schwidetzky, Integrating Subchapters $K$ and S-Just Do It, 62 TAX LAW. 749,799 n.273 (2009).

${ }^{5}$ See Richard Winchester, The Gap in the Employment Tax Gap, 20 STAN. L. \& POL'Y REV. 127, 128 (2009).

${ }^{6}$ Id. at 142 (citing Internal Revenue Service studies of the 2001 tax gap of \$290 billion, \$54 billion of which is underreported employment taxes).

${ }^{7}$ See Lilian V. Faulhaber, The Hidden Limits of the Charitable Deduction: An Introduction to Hypersalience, 92 B.U. L. REV. 1307 (2012). Faulhauber defines hypersalience as occurring
}

when a $[\operatorname{tax}]$ provision is fully — or almost fully—salient, but the limits restricting that provision's application are hidden, or less salient. When revenue-reducing tax provisions are hypersalient, they have a similar effect to hidden taxes: taxpayers inaccurately underestimate their tax burden and thus possibly over-distort their behavior in order to take greater advantage of a tax provision that does not actually provide the benefit they believe it provides.

Id. at 1309. See discussion infra Part II, which explains how the Sub-S Shelter can be hypersalient for entry-level entrepreneurs - they may be more likely to overestimate the benefits of the shelter while

Pitt Tax Review | ISSN 1932-1821 (print) 1932-1996 (online) DOI 10.5195/taxreview.2013.16 | http://taxreview.law.pitt.edu 
taxpayer ${ }^{8}$ - operates here to make the benefits, rather than the burdens, of a tax policy more prominent for a certain group of taxpayers and therefore more likely to change this group's response to the policy. Because entrylevel entrepreneurs' access to cash and other liquid resources at the time of business formation is more limited than that of other entrepreneurs, I argue and provide corroboration that entry-level entrepreneurs are more likely to be persuaded to form an S Corporation to avail themselves of the Sub-S Shelter in an attempt to reduce their employment tax liabilities.

To the extent that the Sub-S Shelter is hypersalient for entry-level entrepreneurs in particular, I show that such hypersalience has two main consequences for the entry-level cohort. First, it can increase the complexity of their choice-of-entity decisions. Absent the Sub-S Shelter, the choice-of-entity decision is, generally speaking, quite straightforward for the typical entry-level entrepreneur. Over the past few decades, socalled "hybrid" entities, such as the limited liability company ("LLC"), have become increasingly popular because they offer virtually unlimited governance and ownership flexibility. Additionally, such entities combine, in their default classification, the single-level income tax advantages of a partnership with the liability protection of a corporation. ${ }^{9}$ However, when the possible employment tax savings that can be obtained through an $\mathrm{S}$ Corporation using the Sub-S Shelter are added to the calculus, the primacy of the LLC can be less clear to the entry-level entrepreneur. She must engage in a complicated process of educating herself about the pros and cons of each entity type. If she is lucky enough to be able to talk to a lawyer, the lawyer must spend time walking her through the countervailing options. ${ }^{10}$ Moreover, assessing how the pros and cons will play out in her

underestimating the extent to which the restrictions on the $\mathrm{S}$ Corporation itself and the opportunity costs of the $\mathrm{S}$ Corporation reduce its value.

${ }^{8}$ See generally Jacob Goldin, Sales Tax Not Included: Designing Commodity Taxes for Inattentive Consumers, 122 YALE L.J. 258, 264-66 (2012); see also Faulhaber, supra note 7, at 1315-18 (extending the concept of salience of a revenue-producing tax to a revenue-reducing tax subsidy).

${ }^{9}$ Throughout this Article, I assume for simplicity that, unless stated otherwise, an LLC has more than one member and does not elect out of its default tax classification (i.e., that it is taxable as a partnership under Subchapter K).

${ }^{10} \mathrm{I}$ also assume that most entry-level entrepreneurs are unrepresented at the formation stage of their businesses or, if they are represented, they are severely constrained in how much legal advice they can afford.

Pitt Tax Review | ISSN 1932-1821 (print) 1932-1996 (online)

DOI 10.5195/taxreview.2013.16 | http://taxreview.law.pitt.edu 
particular business situation requires predicting the likelihood that certain future events will occur. The entry-level entrepreneur is forced to engage in a complicated forecasting exercise precisely at the point at which she faces maximum uncertainty about her business's future. These costs of deliberating about the appropriate entity are deadweight-they are burdensome to the entrepreneur and add nothing productive or valuable to her business or to society at large. ${ }^{11}$ In addition, the incidence of these deliberation costs is distributionally regressive, because the costs are borne by the group of entrepreneurs that has fewest resources to manage them, either by hiring legal counsel or investing in the self-education necessary to navigate the choice.

Second, the hypersalience of the Sub-S Shelter for entry-level entrepreneurs increases the likelihood that members of this group will be induced to distort their choices regarding the appropriate business entity. When an entrepreneur forgoes an entity such as the LLC in favor of the S Corporation due to the prospective tax savings of the Sub-S Shelter, her opportunity cost is any net benefit that the LLC would have delivered had it been chosen instead. In particular, the LLC is remarkably flexible and customizable: it has no restrictions on the types of owners that can invest in the business, nor does it have restrictions on the types of equity that can be issued to its owners. In contrast, the $\mathrm{S}$ Corporation has a number of restrictions in these areas that have the potential to become significant constraints for entrepreneurs seeking to grow their businesses.

These two implications of the regressive salience of the Sub-S Shelter-disproportionately increased deliberation costs for entry-level entrepreneurs tasked with choosing an entity and a greater likelihood of distortion towards the choice of an S Corporation - are troublesome on their own. However, one might ask, even though it is unfortunate that this entry-

\footnotetext{
${ }^{11}$ For helpful intuition on what the deadweight loss from a tax is and how it is calculated, see James R. Hines, Three Sides of Harberger Triangles, J. ECON. PERSP. 167, 175 (1999) (explaining that "Harberger calculates deadweight loss ... [using a] framework [in which] taxes affect prices and distort individual decision-making in spite of the fact that tax revenues are ultimately returned to consumers. Because returning revenue to consumers offsets the amount of taxes that are paid, but does not offset the distortion in individual decision-making, consumers are made worse off by the imposition of the taxes."). The same deadweight loss analysis can be applied to a tax subsidy such as that available through the Sub-S Shelter, although the deliberation costs involved in figuring out the "right" choice of entity in light of the shelter are best thought of as a tax.
}

Pitt Tax Review | ISSN 1932-1821 (print) 1932-1996 (online) DOI 10.5195/taxreview.2013.16 | http://taxreview.law.pitt.edu 
level cohort of entrepreneurs bears more deliberation costs, does it really matter that they choose the wrong entity at the outset of their business operations? Can't they convert out of an S Corporation into a more flexible entity such as the LLC later on? Unfortunately, the background tax rules on entity conversions do not smile on this strategy. Generally, converting an S Corporation to another type of entity is treated as a distribution of assets and a liquidation, which can trigger tax consequences if the corporation's assets have appreciated over time. Conversely, converting from an LLC or another entity taxed as a partnership is much less likely to trigger tax. Therefore, I argue that the distortion of entity choices towards the $\mathrm{S}$ Corporation serves to impose another set of costs on entry-level entrepreneurs - they are denied the "real option value" of the more easily convertible LLC.

Real options capture the idea that waiting can be valuable. A real option is a strategy (which can include a strategy of simply sticking with the status quo) that may have the effect of keeping open one's future choices or flexibility. For the real option to be valuable, the uncertainty surrounding the relevant choice must decrease during the period of waiting. Thus, a company that decides to "wait and see" before investing in a project with an uncertain return can capture real option value if waiting allows it to resolve uncertainty about the profitability of the project.

As applied to the choice-of-entity conundrum facing entry-level entrepreneurs, preserving real option value would involve waiting to form an entity until the entrepreneur knew more about her needs and demands for different entity types. But this type of wait-and-see strategy is unlikely to be advisable for an entrepreneur-forming an entity at the outset of her operations is often easier as a matter of logistics and more protective as a matter of exposure to liability (for instance, the entity can be named in all contracts and documents instead of the entrepreneur personally). In this setting, the strategy most consistent with preserving real option value for the entry-level entrepreneur and her business would be to form an LLC at the outset, because it carries the potential to switch in the future to an $\mathrm{S}$ Corporation or other organizational form at lower cost. But where the hypersalience of the Sub-S Shelter steers entrepreneurs towards the $\mathrm{S}$ Corporation, this conversion flexibility is squandered and real option value is lost. Entrepreneurs choosing the S Corporation may become "locked in" to their choice of an S Corporation because the costs of converting the business from an S Corporation to an LLC are sufficiently steep to

Pitt Tax Review | ISSN 1932-1821 (print) 1932-1996 (online) DOI 10.5195/taxreview.2013.16 | http://taxreview.law.pitt.edu 
overwhelm the benefits. As a result, businesses may be forced to shut down or operate less profitably.

To illustrate more concretely how the hypersalience of the Sub-S Shelter has regressive effects for a typical entry-level entrepreneur, consider the following scenario: a pastry chef who has been laid off from her job at a restaurant seeks to open a small storefront bakery in her community by leveraging her modest savings. The first thing she needs to do is consider whether it makes sense to formalize her business as a separate entity that enjoys limited liability under state law. Immediately, the chef is faced with a decision about which type of entity to form, and must begin educating herself about the factors at stake. For a typical entry-level entrepreneur like the pastry chef, I suggest that the choice-of-entity decision is fairly straightforward if one sets aside the employment tax considerations, including the Sub-S Shelter. Organizing the business as a pass-through entity, taxable under Subchapter K of the Code (such as an LLC in its default classification), rather than as an S Corporation, ensures only one level of tax and supports the future growth of the chef's business by providing flexibility in governance and ownership structures. Absent the Sub-S Shelter, the LLC is likely to trump the S Corporation for the pastry chef.

However, once the pastry chef takes into account employment taxes, the existence of the Sub-S Shelter complicates the superiority of the LLC. By holding out the possibility of sheltering from employment taxes part of her earnings from the business, the Sub-S Shelter is likely to make the $\mathrm{S}$ Corporation at least competitive with, and quite possibly more attractive than, the LLC. Because the pastry chef is concerned about limiting her expenses in the near future while she faces credit and cash constraints, the savings from the shelter will have a high present value to her. ${ }^{12}$ Moreover, the requirements for taking advantage of the Sub-S Shelter-that she must have earnings in excess of a reasonable salary to realize any employment tax savings from the shelter-may not seem relevant to her because she may be overly optimistic that her business will succeed. ${ }^{13}$ As a result, the

\footnotetext{
${ }^{12}$ This high present value results from the entry-level entrepreneur's high personal discount rate. See infra at Part II.A.

${ }^{13}$ The literature documenting optimism as a common and above-average trait of entrepreneurs is robust. See, e.g., Gavin Cassar, Are Individuals Entering Self-Employment Overly-Optimistic? An
}

Pitt Tax Review | ISSN 1932-1821 (print) 1932-1996 (online) DOI 10.5195/taxreview.2013.16 | http://taxreview.law.pitt.edu 
Sub-S Shelter will be hypersalient for the pastry chef, and the $\mathrm{S}$ Corporation will be taken seriously in the choice-of-entity decision. This has the dual result of increasing the chef's deliberation costs and steering her towards an entity that may be poorly suited for her business, especially because the $\mathrm{S}$ Corporation fails to preserve the real option value offered by the possibility of a future conversion.

Given these detrimental impacts of the Sub-S Shelter's hypersalience for entry-level entrepreneurs, what might be an appropriate remedy? I join other scholars in advocating that the Sub-S Shelter be shut down, potentially through a requirement that all business earnings of an owner of a closely-held business (no matter how it is organized) should be subject to employment taxes. The shelter's existence is, after all, unintended from a policy perspective. However, despite many academic and legislative proposals for eliminating the shelter through piecemeal amendments to the employment tax rules or wholesale overhauls of parts of the Code, ${ }^{14}$ little progress has been made in shutting it down. The political opponents of altering the status quo are formidable. Therefore, I offer a proposal that is narrowly tailored to the specific subset of entrepreneurs for whom the SubS Shelter is regressively hypersalient. For this entry-level cohort, I suggest that policymakers combat the shelter's hypersalience by providing targeted information about choice-of-entity to manipulate the salience of the shelter in order to reclaim neutrality as between the LLC and the S Corporation in the choice-of-entity sphere.

Empirical Test of Plans and Projections on Nascent Entrepreneur Expectations, 31 STRATEGIC MGMT. J. 822 (2010).

${ }^{14}$ For instance, the Small Business Modernization Act of 2004, H.R. 4137, 108th Cong. (2004), proposed ending the S Corporation election, but the bill went nowhere. See Winchester, supra note 5, at 145-47 (2009). See also StAFF Of JoInt COMm. On TAXATIOn, 110th CONG., TAX REForm: SElECted Federal Tax Issues Relating to Small Business and Choice of Entity (Comm. Print 2008); Additional Options to Improve TAX Compliance, StafF OF the Joint COMm. on TAX'N (Aug. 3, 2006), available at $\mathrm{http}: / / \mathrm{www}$.finance.senate.gov/newsroom/ranking/download/?id=3f897cf5-1fc248da-a187-bfb4f69fece2; ABA SECTION OF TAXATION COMMENTS ON ADDITIONAL OPTIONS TO Improve TaX Compliance Prepared by the StafF of Joint Comm. On TAX'N (Aug. 3, 2006) and Michael E. Mares, AICPA Forwards Legislative Proposal on Self-Employment Taxes, 98 TAX NOTES TODAY 39-34 (1998).

Pitt Tax Review | ISSN 1932-1821 (print) 1932-1996 (online)

DOI 10.5195/taxreview.2013.16 | http://taxreview.law.pitt.edu 
A vast behavioral economics literature demonstrates the importance of how choices are presented to agents. ${ }^{15}$ Recent public economics scholarship has demonstrated that the way in which a tax is presented to a taxpayer has the potential to make the tax more or less salient, with associated impacts on the tax system's efficiency. ${ }^{16}$ For instance, a policy of adding sales tax on grocery purchases at the cash register rather than displaying the taxinclusive price for each individual item may reduce shoppers' propensity to take the tax into account when making purchasing decisions. ${ }^{17}$ I propose that the salience of the Sub-S Shelter for entry-level entrepreneurs could be adjusted by changing how the tax effects of the shelter are presented relative to other factors at play in the choice-of-entity decision. Moreover, as a low-cost stopgap measure in lieu of changing the underlying legal rules governing the shelter, policymakers should consider exploiting other salience levers, such as providing targeted information.

My proposal shares much in common with one offered by Susan Cleary Morse in the context of tax evasion. ${ }^{18}$ Observing that small businesses and self-employed taxpayers have a high propensity to cheat on their taxes, Morse argues that more salient government communications and greater attention to principles of influence could drastically reduce evasion among this group (which, not incidentally, includes many entrylevel entrepreneurs). ${ }^{19}$ In much the same vein, I propose that the

\footnotetext{
${ }^{15}$ For a general-audience overview of behavioral economics, see RICHARD H. THALER \& CASS R. SunSteIn, NudGE: IMPROVING DeCiSIONS ABOUT HEALTH, WEALTH, AND HAPPINESS (2008).

${ }^{16}$ See, e.g., David Gamage \& Darien Shanske, Three Essays on Tax Salience: Market Salience and Political Salience, 65 TAX L. REV. 19 (2011) (discussing efficiency costs of high-salience taxes and related policy implications).

${ }^{17}$ See Raj Chetty et al., Salience and Taxation: Theory and Evidence, 99 AM. ECON. REV. 1145 (2009); see also Marika Cabral \& Caroline Hoxby, The Hated Property Tax: Salience, Tax Rates, and Tax Revolts (Nov. 2010) (unpublished manuscript), available at http://economics.stanford.edu/ files/Hoxby3_2.pdf (examining the case of property taxes permitted to be paid by escrow; finding lower salience).

${ }^{18}$ See Susan Cleary Morse, Using Salience and Influence to Narrow the Tax Gap, 40 Loy. U. CHI. L.J. 483 (2009).

${ }^{19}$ Id. at 503-07 (documenting the surprising lack of attention to salience in government communications to taxpayers). For cash-based businesses in particular, Morse shows that taxpayer information is strikingly non-salient - in regard to a government fact sheet on "Business Income and the Tax Gap," Morse notes that "[n]ot until the second paragraph of the second section is there [the] key piece of information"- that self-employed taxpayers must report their cash earnings. Id. at 503.
}

Pitt Tax Review | ISSN 1932-1821 (print) 1932-1996 (online) DOI 10.5195/taxreview.2013.16 | http://taxreview.law.pitt.edu 
government should offer targeted information to entry-level entrepreneurs to educate them about the costs of the Sub-S Shelter, as well as the benefits of the LLC. The goal of the campaign would be to "nudge" taxpayers away from viewing the Sub-S Shelter as a commanding dimension of their choice-of-entity decision. Rather than seeking to steer entry-level entrepreneurs towards a particular entity, the targeted information would attempt to neutralize the hypersalience of the Sub-S Shelter. In this sense, the information would be designed to assist entry-level entrepreneurs in correcting tendencies to overvalue the short-term tax savings of the shelter while under-valuing the longer-term flexibility of the LLC. One could imagine that these targeted communications would acknowledge the existence of the Sub-S Shelter but might also emphasize the risks of its use-including the risk that the shelter might attract audit scrutiny from the Internal Revenue Service ("IRS") - and highlight the ways in which an LLC could foster long-term growth due to its flexibility and ease of conversion. Such information could have a substantial impact on how entry-level entrepreneurs perceive and respond to the entity choice problem given the existence of the Sub-S Shelter.

There are many ways that the government could experiment with providing such targeted information, and this Article offers a nonexhaustive set of possibilities for discussion. First, the government could simply communicate with the entry-level entrepreneurs through channels that they already access, such as the Internet or legal assistance websites. Second, the IRS might produce a publication discussing choice-of-entity for entry-level entrepreneurs in particular. No general publication on choice-ofentity exists, nor does one drafted with the needs of the entry-level cohort in mind. If such a publication were offered, it could highlight the benefits of choosing a more flexible entity like the LLC, while informing taxpayers of the risks and potential long-term costs of using the Sub-S Shelter in an S Corporation. Third, the government could provide training materials to, or host workshops for, agencies and organizations, such as local business planning groups and chapters of the Small Business Administration, to emphasize the benefits of choosing an LLC as a business vehicle. Fourth, the IRS could reach out to individual states - the level at which individuals actually form their entities - to help tailor choice-of-entity information for entry-level entrepreneurs on their websites or in state-level publications. While there are countless possibilities for policies that also could help nudge the salience of the Sub-S Shelter for entrepreneurs towards neutrality, I advocate the pursuit of a targeted information campaign as a

Pitt Tax Review | ISSN 1932-1821 (print) 1932-1996 (online) DOI 10.5195/taxreview.2013.16 | http://taxreview.law.pitt.edu 
viable first step towards addressing the regressive consequences of the SubS Shelter.

Using information as a lever to affect salience for a particular group of taxpayers has clear potential to improve the equity and efficiency of the tax system at a low administrative cost. And, while it may seem paradoxical that an already-complex choice could be simplified for unsophisticated taxpayers by adding more information into the mix, the targeted information would be designed to mitigate the prominence of the one factor - the possible employment tax savings from the Sub-S Shelter-that complicated the choice-of-entity decision for entry-level entrepreneurs in the first place.

In Part I.A of this Article, I review the choice between the $\mathrm{S}$ Corporation and the LLC for entry-level entrepreneurs. I show that, but for the impact of the Sub-S Shelter, the LLC structure generally will be preferable for a typical entry-level entrepreneur. Part I.B reviews the nuts and bolts of the Sub-S Shelter. Part II argues that the attributes of the Sub-S Shelter interact with characteristics common to entry-level entrepreneurs to make the shelter's potential tax savings hypersalient for this cohort, and then documents the regressive implications of this hypersalience by characterizing the Sub-S Shelter as a call option. Part III explores ways in which the Sub-S Shelter call option can be restructured to preserve real option value through the provision of targeted information to nudge entrylevel entrepreneurs towards neutrality in the choice-of-entity decision. Part IV concludes.

\section{ENTREPRENEURS' CHOICE-OF-ENTITY PROBLEM IN A NUTSHELL: WITH AND WITHOUT THE SUB-S SHELTER}

One of the first legal questions confronting entrepreneurs like the pastry chef as they prepare to open their ventures for business is whether to take advantage of applicable state laws to create a new legal entity for their nascent businesses and, if so, which type of entity to choose. An in-depth discussion of the nuances of counseling entrepreneurs on how to choose a business entity is not the objective here. However, comprehensive 
treatments can be found elsewhere. ${ }^{20}$ Instead, the purpose of this Part is to show that, absent the Sub-S Shelter, the choice-of-entity decision for the typical entry-level entrepreneur is straightforward. But, when the shelter is taken into consideration, the decision becomes more complicated. Here, I argue that the LLC will generally trump the choice of a state law corporation even if an election to be treated as an $\mathrm{S}$ Corporation is made. Subpart A walks through the generally-relevant factors to make this claim, leaving the Sub-S Shelter aside. Subpart B describes how the fairly straightforward calculus becomes complicated by the presence of the Sub-S Shelter.

\section{A. Choice-of Entity in a World Without the Sub-S Shelter}

\section{Is a Separate Entity Necessary?}

Under state law, starting a business does not require establishing an entity recognized as being separate from its owners. Absent an affirmative choice to create such an entity, the pastry chef's dessert business would exist as a sole proprietorship. ${ }^{21}$ However, to obtain certain legal protections,

${ }^{20}$ See, e.g., Schwidetzky, supra note 4, at 759-801. See also Dwight DraKe, BuSINESS PlanNing: Closely Held ENTERPRISES 38-39, 165-78 (2d ed. 2008); JAMES S. Eustice \& Joel D. Kuntz, Federal InCOME TAXATION OF S CORPorations 2.03 (2013) (providing an item-by-item discussion of advantages and disadvantages of S Corporations, C Corporations, partnerships, and limited liability companies in selected areas); ANTHONY MANCUSO, LLC OR CORPORATION? HOW TO CHOOSE THE RIGHT FORM FOR YOUR BuSINESS (2d ed. 2006); JEFFREY A. JENSEN ET AL., TiPS AND TRAPS WHEN INCORPORATING YOUR BusinesS (2005); William R. BisCHOFF, CHOOSING THE Right Business Entity: TAX Practitioner's Guide (2001); JANE V. HAWKes, ChOICE OF ENTITY: LeARN How to Choose the Most Appropriate Vehicle for Your Clients' Business, TaX and Legal ISSUES (2000).

${ }^{21}$ If the chef had a business partner with whom she shared some of the earnings from the business, it would exist as a general partnership. Under the Revised Uniform Partnership Act (the "RUPA"), which has been adopted by many states, a partnership is "an association of persons who carry on as co-owners of a business for profit. ...” R.U.P.A. § 202(a) (2012). Unless the two partners drafted a partnership agreement to implement their own rules for the operation of their partnership, the RUPA would determine how the owners would share profits, divide losses, bear liability for debts and obligations of the partnership, and many other important issues. Even if they decided to draft their own partnership agreement to customize rules for their relationship that might be a better fit than the default rules of the RUPA, there are limitations to this "private law" contract solution as applied to a general partnership. See id. § 103 ("[t]o the extent that the partnership agreement does not otherwise provide, this Act governs relations among the partners and between the partners and the partnership"). In particular, limited liability would not be available unless the partners formed the business as a separate entity under state law.

Pitt Tax Review | ISSN 1932-1821 (print) 1932-1996 (online)

DOI 10.5195/taxreview.2013.16 | http://taxreview.law.pitt.edu 
such as limited liability, the entrepreneur must create a separate legal entity registered with, and recognized by, the government.

Limited liability depends on the legal separation between an owner's personal assets and those of the business of which she is an owner. ${ }^{22}$ Each owner of a business is limited in her liability for debts of or judgments against the business up to the amount of such owner's investment in the entity or, equivalently, an owner's share of the business's assets. It is likely that the pastry chef will want to form a separate entity with liability protection. This is because of legal liabilities ranging from tort foreseeable important for bricks-and-mortar food businesses to contract (breach or liability therefor). Without a separate entity that offers limited liability, if the business incurred any such liabilities and the assets of the business (i.e., an insurance policy, any funds in the business's bank account and any property owned by the business) were insufficient to cover them, the chef would be required to use her own personal assets, such as savings or personal property, to cover the shortfall. ${ }^{23}$

In the case of a relatively simple business that appears to carry minimal risk of injuring someone and that has small dollar amounts at stake in contracts with its customers and suppliers, an entrepreneur may decide quite rationally not to create a separate entity, as this entails paying annual fees, observing certain "formalities" discussed further below, and taking other costly steps necessary to keep the entity in existence. ${ }^{24}$ But, for most businesses, the potential liability exposure is typically the motivating nontax reason for forming a separate entity under state law that entitles each of

${ }^{22}$ See, e.g., John H. Matheson, The Limits of Business Limited Liability: Entity Veil Piercing and Successor Liability Doctrines, 31 WM. Mitchell L. ReV. 413, 413-16 (2005) (discussing the notion of separating business assets among different entities, or business assets from personal assets, as "entitybased limited liability").

${ }^{23}$ Contra Franklin A. Gevurtz, Business Planning 59 (4th ed. 2008) (pointing out that it behooves the counselor to consider the situations of the particular owners involved, and how much they might lose in the worst-case scenario of having to declare personal bankruptcy).

${ }^{24} I d$. at $62-63$ (advising that "[i]ndiscriminate use of the corporate form will frequently result in a counter-productive situation in which expense, time and formality will far outweigh any benefit to the enterprised.").

Pitt Tax Review | ISSN 1932-1821 (print) 1932-1996 (online) DOI 10.5195/taxreview.2013.16 | http://taxreview.law.pitt.edu 
its owners to "limited liability." 25 While this protection is never absolute and entrepreneurs must take affirmative steps to preserve it various points in their business endeavors, ${ }^{26}$ it is an important opportunity to reduce risk and understandably allows many entrepreneurs, and their families, to rest better at night.

2. What Are the Primary Separate-Entity Options for Entry-Level Entrepreneurs?

For most entry-level non-professional businesses (i.e., other than a medical office, law office or other regulated practices) that do not seek access to public capital markets, there are generally two dominant state law options for obtaining limited liability: an S Corporation or an LLC. ${ }^{27}$

\section{a. The S Corporation}

If an entrepreneur like the pastry chef selected a state law corporation to house her fledgling business, she may be eligible to make a federal tax election that allows her business to be treated as a so-called " $\mathrm{S}$ Corporation" for federal income tax purposes. ${ }^{28}$ The election is available only under specific circumstances, but making the election turns the state law corporation from a tax-disadvantaged entity into a tax-advantaged entity. There are four key restrictions, ${ }^{29}$ which come directly from the Code:

${ }^{25}$ See David A. Rubenstein \& Jeffrey S. Shamberg, Considerations in Electing S Corporation Status, in LIMITED LIABILITY COMPANIES AND S CORPORATIONS 13-2, 13-5 (2005) ("limiting liability is generally the key nontax consideration in favor of using a corporation or an LLC ....").

${ }^{26}$ Limited liability of a legal entity is not always respected by courts, particularly when the entity has been thinly capitalized, treated by the owner(s) as their own "alter ego" (that is, as an extension of themselves, often characterized by a commingling of personal and business assets and an absence of arms-lengths dealings between the entity and the owners) or other transgressions. The possibility that an entity's "corporate veil" will be "pierced" is something that all counselors should discuss with their clients to counter the erroneous conclusion that limited liability is absolute.

${ }^{27}$ Many jurisdictions have authorized other types of entities by statute that carry the advantage of limited liability, such as the professional service corporation, the limited liability partnership, the limited liability limited partnership, and other permutations thereof. See, e.g., the Illinois Professional Service Corporation Act, 805 ILl. COMP. STAT. 10 (2005 \& Supp. 2012).

${ }^{28}$ See Internal Revenue Service, Instructions for Form 2553, IRS.GOV, 1 (Dec. 2007), http://www .irs.gov/pub/irs-pdf/i2553.pdf.

${ }^{29}$ These are the "headline" restrictions of Subchapter S, but there are others, including the prohibition on an $\mathrm{S}$ Corporation is subject to corporate-level tax at the highest corporate tax rate (currently $35 \%$ ) on its excess net passive income if the corporation has accumulated earnings and profits

Pitt Tax Review | ISSN 1932-1821 (print) 1932-1996 (online)

DOI 10.5195/taxreview.2013.16 | http://taxreview.law.pitt.edu 
(1) the corporation must have 100 or fewer shareholders; (2) each shareholder must be a person (other than an estate, certain trusts, or certain tax-exempt organizations) who is an individual, rather than an entity; (3) no shareholder may be a nonresident alien; and (4) the corporation may only have "one class of stock," meaning that each share of stock of the corporation must have identical rights (although it is permissible to issue common stock with and without voting rights so long as all other rights are identical). ${ }^{30}$

Assuming that these criteria are met, making the $\mathrm{S}$ election changes nothing for the corporation under state law, but for federal income tax purposes, the entity is taxed under Subchapter S, rather than Subchapter C, of the Code. There are substantial differences in tax treatment under these two subchapters, the most significant of which is that an S Corporation faces only one level of tax. The income of the business is attributed directly ("passed through") to the business's owners, and such individuals pay tax on this income, but there is no tax assessed at the entity level. Thus, being taxed under Subchapter S avoids the popularly-known result of "double taxation" that applies to C Corporations. This will be advantageous to the entrepreneur to the extent that (a) the business has income in excess of expenses, including salaries and payments for services, ${ }^{31}$ and (b) the entrepreneur's individual marginal tax rate is less than the marginal tax rate

at the close of the taxable year and gross receipts more than $25 \%$ of which are passive investment income. Worse yet, an S Corporation election can be terminated if these factors are present for each of three consecutive taxable years. See I.R.C. $\S \S 1375$ (imposing corporate-level tax), 1362(d)(3) (terminating the $\mathrm{S}$ election). Note that the recent small business tax reform proposal from Representative Dave Camp would greatly alleviate these restrictions. See COMM. ON WAYS AND MEANS, U.S. HouSE of Representatives, TeChNical Explanation of the Ways and MEans Committee Discussion DRAFt PROVISIONS TO REFORM THE TAXATION OF SMALl BusinESS AND PASSTHROUGH ENTITIES 14 (2013), available at http://waysandmeans.house.gov/uploadedfiles/final_sm_bus_passthrough_ technical_explanation_03_12_13.pdf.

${ }^{30}$ See I.R.C. $\S 1361(\mathrm{~b})(1)(\mathrm{A})-(\mathrm{D})$.

${ }^{31}$ Simply because a business is organized as a C Corporation does not imply that it will incur corporate-level tax: this occurs, generally, where a business is generating revenues in excess of its deductible expenses, thus causing it to have net taxable income at the entity level. As Walter Schwidetzky notes, "C corporations often seek to 'zero out' their income by, among other things, paying deductible salaries to shareholder-employees, paying deductible interest to shareholder-creditors, and paying deductible rent to shareholder-landlords. Many a lawyer has become enriched doing battle in court over what counts as a reasonable salary, a reasonable amount of debt, or a reasonable amount of rent." Schwidetzky, supra note 4, at 755.

Pitt Tax Review | ISSN 1932-1821 (print) 1932-1996 (online) DOI 10.5195/taxreview.2013.16 | http://taxreview.law.pitt.edu 
faced by the corporation. ${ }^{32}$ For the typical entry-level entrepreneur not seeking to exit her business through an initial public offering (in which case the $\mathrm{C}$ Corporation is likely to be required), the $\mathrm{S}$ Corporation is often a viable legal entity. ${ }^{33}$

\section{b. The $L L C$}

The LLC, the second entity option considered by most entry-level entrepreneurs, is a more modern innovation than the traditional corporation. It is often called a "hybrid" because it provides liability protection similar to a corporation while offering, when it is in its default tax classification, a single level of taxation similar to that available under Subchapter S. ${ }^{34}$ In

\footnotetext{
${ }^{32}$ Despite the off-putting "double-tax" designation, it is important to recognize that the doubletaxation structure itself is not the feature that produces a disincentive to operate in corporate form for many profitable entities. Rather, it is the magnitude of the tax rates applied at each level, entity and owner. The double-taxation structure under current law taxes earnings at the entity level at the applicable corporate graduated rates (which range from $15 \%$ up to $35 \%$ ), but the after-tax amounts that are then distributed out to owners are treated as ordinary income after the expiration of the Bush tax cuts, with marginal rates that are now as high as $39.6 \%$ for individuals. However, income from a domestic corporation would generally be considered a "qualified dividend" and be given preferential tax treatment (a 15\% rate under current law). See I.R.C. $\S 1(\mathrm{~h})(11)(\mathrm{B})$ (defining "qualified dividend income" as dividends received during the taxable year from domestic corporations and qualified foreign corporations); see also Boris I. BitTKER \& JAMES S. Eustice, FEDERAL INCOME TAXATION OF CORPORATIONS \& SHAREHOLDERS 8.01 (2013). In addition, a recent news article about the effect of the new $39.6 \%$ bracket on the entity decisions of entrepreneurs cites a survey statistic that $35 \%$ of owners of small businesses with between $\$ 1$ million and \$20 million in annual revenues would consider switching from an S Corporation to a C Corporation to minimize income taxes. See Emily Maltby, Firms Puzzle Over Tax Riddle, WALL St. J., Feb. 20, 2013, http://online.wsj.com/article/ SB10001424127887323764804578314583989674920.html?mod=WSJ_hps_LEFTTopStories.

${ }^{33}$ Certain sophisticated investors seeking a return on their investment via an initial public offering require that all businesses in which they invest be organized as a C Corporation to avoid costly changes down the road. Moreover, one commentator has shown that taxation under Subchapter C may often be more advantageous for a small-income, profitable, privately-held C Corporation owned by high-income shareholders than taxation under Subchapter $\mathrm{S}$ or Subchapter K, which governs the tax treatment of entities treated as partnerships for federal income tax purposes. See John W. Lee, A Populist Perspective of the Business Tax Entities Universe, 78 TEX. L. REV. 885, 903-07 (2000). These advantages would not be present for the low-to moderate-income entrepreneur nor would they attach in the event that the business generated a loss, rather than a profit, in a given taxable year (because C Corporations cannot "pass through" annual losses to its shareholders as can S Corporations and entities treated as partnerships for tax purposes). See I.R.C. $\S \S 336$ (C Corporation), 705 (Subchapter K partnership), 1366 (S Corporation).

${ }^{34}$ See Winchester, supra note 5, at 132 (explaining that the LLC default rules depend on whether it has one member or more than one - if it has only one member, "the firm will be disregarded for tax purposes and the owner will be treated the same as if it were a sole proprietor, causing the business earnings to be taxed as if they were derived by the owner directly, not through a business entity"). And
}

Pitt Tax Review | ISSN 1932-1821 (print) 1932-1996 (online)

DOI 10.5195/taxreview.2013.16 | http://taxreview.law.pitt.edu 
addition, the LLC's formalities and annual maintenance requirements, such as filing an annual report with the state, are generally minimal. Finally, there are no restrictions on who may hold an equity interest in an LLC (called a "membership" interest). These features, and how they affect the choice between the LLC and the S Corporation, will be discussed further in Part I.A.3 of this article.

\section{The Case Against the S Corporation}

Due to the restrictions on $\mathrm{S}$ Corporation eligibility outlined above, not all businesses will be able to make the election to be taxed under Subchapter S. Even if the business can accommodate the restrictions at the outset of its operations, two of the four restrictions outlined above-the requirement that all shareholders are individuals and that the corporation has only one class of stock - may become significant constraints for the business in the future as it grows. ${ }^{35}$ In addition, in the event that the entrepreneur decides that the choice to operate her business as an $\mathrm{S}$ Corporation was misguided, conversion out of Subchapter $\mathrm{S}$ is likely to entail substantial costs. The following subsections elaborate on these three drawbacks associated with the S Corporation as an entity choice for entrylevel entrepreneurs.

\section{a. Limitation on Shareholders May Shut Out Investors}

In practice, the $\mathrm{S}$ Corporation restriction that limits the business to having shareholders that are individuals rather than entities excludes most passive investors who may be interested in taking equity in the business once it begins growing. Investors typically make their investments through limited liability pass-through entities (i.e., limited partnerships or LLCs). For example, almost all angel investors and all private equity funds will

where the LLC has more than one member, the default classification is Subchapter K (taxation as a partnership). However, one of the advantages of the LLC is the flexibility of its tax-status - it can be taxed under subchapter $\mathrm{C}$ or subchapter K pursuant to the so-called "check the box" regulations. See Treas. Reg. § 301.7701-1 to -3 (as amended in 2006). See also I.R.S. Priv. Ltr. Rul. 200818017 (May 2, 2008); Winchester, supra note 5, at 131, 145-46.

${ }^{35}$ For instance, one of the most cumbersome $\mathrm{S}$ Corporation requirements, as discussed further below, has been dubbed "the one class of stock straightjacket" by a commentator. See Jerald David August, Benefits and Burdens of Subchapter $S$ in a Check-the-Box World, 4 Fla. TAX REV. 287, 320-22 (1999).

Pitt Tax Review | ISSN 1932-1821 (print) 1932-1996 (online) DOI 10.5195/taxreview.2013.16 | http://taxreview.law.pitt.edu 
have an entity through which its constituent individuals make investments; such investors will be reluctant to hold ownership shares directly because of the possible risks of veil-piercing and exposure to other liabilities. ${ }^{36}$ Although an entry-level entrepreneur may not consider having to accommodate investors who want (or need) to hold their equity interest through an entity, this may be a concern that arises later as the business seeks to expand and access other sources of capital. And, as will be revealed below, converting to a different type of entity once the business is up and running and has going-concern value as an $\mathrm{S}$ Corporation is complicated and can be costly.

\section{b. One Class of Stock Limits Growth}

Perhaps even more significant is the fourth S Corporation restriction, requiring that the business have only one class of stock. This limits the flexibility of the enterprise to bring in new equity holders on customized terms that may help achieve the parties' objectives in two particularly constricting ways. First, "one class of stock" means that an owner must have the same income rights, loss rights, cash flow rights and liquidation rights as every other owner. This requirement precludes issuing another series of shares with rights that diverge from those of the common stock holders. ${ }^{37}$

For example, an $\mathrm{S}$ Corporation that began its existence wholly-owned by the founding entrepreneur (i.e., the founder owned 100 percent of the corporation's common shares) would be precluded from issuing stock to an

\footnotetext{
${ }^{36}$ See Victor Fleischer, Taxing Blackstone, 61 TAX L. REV. 89 (2008) (discussing the creative measures taken by companies such as Blackstone, which "thumbed its nose at Congress, cleverly structuring its way around the corporate tax. It relied on self-help, using the combination of a blocker entity and the treatment of carried interest as capital gain to punch a loophole in the publicly-traded partnership rules." Id. at 114.). See also Private Equity Funds, 735 TAX MGMT. PORT. (BNA) A-13 (2004) ("Virtually every U.S. private equity fund, with the exception of certain parallel entities, is structured as a pass-through entity for tax purposes.").

${ }^{37}$ See August, supra note 35, at 298 (noting the prohibition against issuing shares with liquidation or distribution preferences is just the tip of the iceberg: "Even buy-sell agreements and similar arrangements must be sanitized to avoid a prohibited second class of stock. A buy-sell agreement, agreement to restrict the transferability of stock, or cross-purchase and redemption agreement creates a prohibited second class of stock if a principal purpose of the agreement is to circumvent the one class requirement and the agreement establishes a redemption or purchase price that, at the time the agreement is made, is significantly below or in excess of the stock's fair market value.").
}

Pitt Tax Review | ISSN 1932-1821 (print) 1932-1996 (online)

DOI 10.5195/taxreview.2013.16 | http://taxreview.law.pitt.edu 
angel investor who wanted a so-called "preferred" return. ${ }^{38}$ The attractiveness of preferred stock stems from its hybrid attributes of both debt and equity. ${ }^{39}$ The preferred stockholder receives her yield on a periodic basis for a specific amount of time before any dividends can be paid on common shares and, if the firm is liquidated, she gets priority over common shareholders in recovering her investment. Preferred stock is regularly used by angel investors, private equity firms, and venture capital companies to structure incentives for a successful investor/entrepreneur relationship and to allocate risk of loss across the parties. ${ }^{40}$ Absent this financing arrangement precluded by the S Corporation one-class-of-stock restriction, investors may demand a higher percentage of common stock control than the entrepreneur is willing to surrender.

Second, as suggested by the "one class" description, the distributions received by each owner in an S Corporation must be proportional to the owner's equity stake in the $\mathrm{S}$ Corporation. ${ }^{41}$ For example, suppose that the pastry chef has a business partner with whom she was opening the business.

${ }^{38}$ See C, K, or S: Exploring the Alphabet Soup of Small Business Choices in Advance of Tax Reform: Hearing Before the S. Comm. on Fin., 110th Cong. 57 (2008) (statement of Samuel P. Starr, Adjunct Professor of Law, Georgetown University Law Center) ("the one-class of stock restriction ... is intended to keep Subchapter S simple. However, it limits S Corporation access to capital."). See also August, supra note 35, at 319-21 (exploring possible fixes to the "one class of stock" rule).

${ }^{39}$ See Erik Berglöf, A Control Theory of Venture Capital Finance, 10 J.L. ECON. \& 247, 248 (1994) (explaining "the combined use of debt and equity or, more commonly, convertible preferred stock or convertible debt [as protecting] ... the initial contracting parties as much as possible against dilution and extracts from a future buyer of the firm.”).

${ }^{40}$ See August, supra note 35, at 320 (arguing that "[t]he one class of stock rule ... unfairly restricts an S corporation's access to venture capital and more sophisticated forms of financing. Commercial lenders, in addition to fixed payments of interest, frequently insist on receiving equity-like payments ... as consideration for the risk they assume. Often, a commercial lender will extend financing only if it receives a right to convert its debt into equity. No similar tax penalty applies to hybrid or equity-flavored debt of an entity taxable as a partnership." The commercial lender's extension of financing solely on the basis of receiving a right to convert its debt into equity is impossible under the one class of stock restriction for an S Corporation.).

${ }^{41}$ The "one class of stock" requirement means that the economic rights of all shares of an $\mathrm{S}$ Corporation must be identical. See Treas. Reg. §1.1361-1(1)(1) (2012) ("a corporation is treated as having only one class of stock if all outstanding shares of stock of the corporation confer identical rights to distribution and liquidation proceeds"). However, voting rights can differ. The Code provides that a corporation "does not have more than one class of stock solely because of differences in voting rights among shares of common stock." I.R.C. §1361(c)(4); see also EUSTICE \& KUNTZ, supra note 20, ๑ $3.08[2]$.

Pitt Tax Review | ISSN 1932-1821 (print) 1932-1996 (online) DOI 10.5195/taxreview.2013.16 | http://taxreview.law.pitt.edu 
Each owns fifty of their S Corporation's one hundred shares of issued and outstanding stock. As a result, they will each receive the same amount if and when they decide to make dividend-like distributions from the corporation, and they will share equally in any losses generated by the business. Similarly, if they split the ownership sixty-forty, the chef would receive sixty percent of the income and losses to her partner's forty percent of income and losses. This strict pro-rata approach contrasts with the more flexible Subchapter K partnership tax rules that allow so-called "special allocations" of income and losses among owners, so long as the special allocations have "substantial economic effect." ${ }^{\text {"42 }}$ Under Subchapter K, the two entrepreneurs would have the option to allocate the business's income sixty-forty and the losses thirty-seventy if they formed an LLC taxed as a partnership instead of an S Corporation. Such customized allocations might be chosen for a number of reasons; for instance, to give the chef, if she were the manager, an additional incentive to generate profits without saddling her with an outsized share of the losses. Thus, choosing an LLC gives entrepreneurs maximum flexibility to structure their ownership incentives in way that will maximize the business's value and prospects for success.

Not only can the S Corporation's restrictions impose burdensome limits on the ability of an entrepreneur to create the kind of ownership structure she wants from the outset, but violating one of the S Corporation restrictions, thus terminating the S-election, can happen under a number of easily-imaginable circumstances. This risk frequently comes to the forefront in the context of distinguishing between the debt and equity interests of the business. If debt of an $\mathrm{S}$ Corporation has equity-like characteristics, it may be vulnerable to re-characterization as equity by the IRS upon audit. ${ }^{43}$ Moreover, re-characterizing the corporation's debt as

${ }^{42}$ I.R.C. § 704(b); Treas. Reg. § 1.704-1(b) (2012). A cursory discussion of these rules is beyond the scope of this Article. Generally, an allocation that does not produce a capital account deficit for any member of the LLC will be respected under the "substantial economic effect" standard if capital accounts are maintained for each member in accordance with the Treas. Reg. § 1.704-1(b) and, in the event of liquidation of the LLC, liquidating distributions are made in accordance with positive capital accounts. For a discussion on these rules, see NoEl B. CunNingham \& LAURA CunNingham, ThE LOGiC OF SUbChapter K: A CONCEPTUAL GUide to the TAXATION OF PARTNERShiPS (3d ed. 2006).

${ }^{43}$ There is a "straight-debt" safe harbor for S Corporations, under which a fixed written obligation to pay a sum certain on demand or on a specified due date that bears non-contingent interest, is not convertible into equity of the S Corporation, and is held only by persons who can be shareholders

Pitt Tax Review | ISSN 1932-1821 (print) 1932-1996 (online)

DOI 10.5195/taxreview.2013.16 | http://taxreview.law.pitt.edu 
equity can cause the business to run afoul of the Subchapter $\mathrm{S}$ restrictions in a number of ways, according to one commentator:

(1) the debt deemed equity may be a second class of stock, (2) the purported debt may be held by a person, such as an alien, who cannot be a shareholder of an S Corporation or (3) the shareholder number limitation may be exceeded when the debt holder is counted as a shareholder. ${ }^{44}$

If one of the restrictions is violated, the election to be treated as an $\mathrm{S}$ Corporation terminates, and the corporation would automatically revert to being a "regular" corporation, taxed under Subchapter C of the Code. Among other consequences, this reclassification would trigger "double tax" on any taxable income earned by the corporation.

\section{c. Conversion Has Negative Tax Consequences}

What happens if the entrepreneur decides to start out as an $\mathrm{S}$ Corporation and later changes her mind, opting instead for an LLC? The choice to convert from one entity type to another might occur at the time the business is ready to take on investors or change its structure in ways that would violate the Subchapter S restrictions. Unfortunately, converting from an $\mathrm{S}$ Corporation to a non-corporate entity ${ }^{45}$ generally has tax consequences. ${ }^{46}$ A conversion from an S Corporation to an LLC is treated for tax purposes as a liquidation of the corporation and a distribution of the corporation's assets to its shareholders, followed by their contribution of

of an S Corporation is deemed not to be a second class of stock that would terminate S Corporation status. See I.R.C. § 1361(c)(5).

${ }^{44}$ James S. Eustice, Subchapter S Corporations and Partnerships: A Search for the Pass Through Paradigm (Some Preliminary Proposals), 39 TAX L. REV. 345, 363 (1984).

${ }^{45}$ If the entrepreneur seeks to convert from an S Corporation to a C Corporation, the conversion is straightforward. The S election can be terminated by "revocation" where more than one-half of shares consent to revocation. See I.R.C. $\S 1362(d)(1)(B)$. There is no need to transfer assets or liabilities, no deemed liquidation, no new entity for tax purposes. Instead, there is an "S short year" and a "C short year" to which items of items of income, loss, deduction, or credit are taken into account on a pro-rata basis, generally speaking. See I.R.C. § 1362(e)(1), (2); see also DRAKE, supra note 20, at 168-69.

46 See August, supra note 35, at 331-33 (offering some techniques to mitigate the tax consequences of a conversion from a corporation - whether S or C - to a partnership but concluding that it is generally difficult to overcome the "handicap" and noting that any reforms to consolidate Subchapters $\mathrm{S}$ and $\mathrm{K}$ must include "very liberal transitional rules ... to reduce the tax cost from converting to from $\mathrm{C}$ to $\mathrm{K}$ or $\mathrm{S}$ to $\mathrm{K}$ status.").

Pitt Tax Review | ISSN 1932-1821 (print) 1932-1996 (online) DOI 10.5195/taxreview.2013.16 | http://taxreview.law.pitt.edu 
those assets to a new LLC. ${ }^{47}$ The first step is a taxable event-if assets in the $\mathrm{S}$ Corporation have appreciated, the gain will be passed through to the shareholders, who will owe tax unless they can offset this gain with other losses. ${ }^{48}$ Although the basis of the assets of the old S Corporation will be stepped up to fair market value before they are contributed to the new LLC, a transaction that causes tax to become due without generating any cash to pay the tax is highly unfavorable from the entrepreneur's perspective. It reduces her real option value of choosing an S Corporation as discussed in Part III.

\section{The Case for the LLC}

In addition to avoiding the restrictions specific to the $\mathrm{S}$ Corporation, the LLC has a number of positive attributes from a state-law perspective and a tax perspective that make it independently attractive as an entity choice for entry-level entrepreneurs.

\section{a. Maximize Liability Protection Under State Law}

Although there is variation from state to state regarding how LLC statutes demarcate the boundaries of limited liability, a number of jurisdictions' LLC statutes go farther in protecting owners than do corresponding business corporation statutes (which would govern the $\mathrm{S}$ Corporation). For example, the Illinois legislature amended its LLC statute in 1998 to remove language "which explicitly provided that a member or manager of an LLC could be held personally liable for her own actions or for the actions of the LLC to the same extent as a shareholder or director of a corporation could be held personally liable." 49 The amended language holds that " $[\mathrm{t}]$ he failure of a limited liability company to observe the usual company formalities or requirements relating to the exercise of its company powers of management of its business is not a ground for imposing personal liability on the members or managers for liabilities of the company," ${ }^{, 0}$ and

\footnotetext{
${ }^{47}$ Generally, section 331 of the Code applies to a complete liquidation of an S Corporation. See William R. Christian \& IRVIng M. GRANT, SubChapter S TAXATION 28.11 (4th ed. 1997); see also I.R.C. $\S \S 331$ (a), 336(a), (d) (setting forth exceptions to loss recognition).

${ }^{48}$ I.R.C. $\S 1363(\mathrm{a})$.

${ }^{49}$ Puleo v. Topel, 368 Ill. App. 3d 63, 69 (Ill. App. Ct. 2006).

${ }^{50} 805$ ILl. COMP. STAT. 180/10-10(c) (2005).
}

Pitt Tax Review | ISSN 1932-1821 (print) 1932-1996 (online) DOI 10.5195/taxreview.2013.16 | http://taxreview.law.pitt.edu 
thus provides greater protections than in the case of a corporation formed under the Illinois Business Corporation Act. ${ }^{51}$ However, despite this additional protection against claims by third parties against the personal assets of members in cases where company formalities are disregarded, or a member or manager of an LLC acts on behalf of the LLC without proper authority, courts have made clear that the doctrine of veil-piercing applies to LLCs as it would to corporations in such cases as fraud, alter-ego, and undercapitalization. $^{52}$

Additionally, under many LLC statutes, a membership interest in an LLC is considered to be personal property. The rights of a creditor of a member of an LLC are limited to obtaining a so-called "charging order" against the debtor/member's right to distributions on account of her membership interest. ${ }^{53}$ The charging order allows the LLC to continue to operate without further interference from the creditor, who will not accede to the debtor/member's right to vote on issues pertaining to the LLC, will not be permitted to inspect or copy records, and will not be able to exercise any other rights of the debtor/member with respect to the management of the LLC's business. ${ }^{54}$ This treatment contrasts with the remedies available to a creditor of a debtor/shareholder of a corporate entity: such a creditor potentially could foreclose and obtain full ownership of such debtor/shareholder's stock, including all voting and other rights to control the corporation. ${ }^{55}$

\footnotetext{
${ }^{51}$ See id. 5/3.20 (2005) (providing that an unauthorized use of corporate powers shall result in the shareholders being "jointly and severally liable for all debts and liabilities incurred or arising as a result thereof.").

${ }^{52}$ See, e.g., Westmeyer v. Flynn, 889 N.E.2d 671, 678 (Ill. App. Ct. 2008) (finding that, where statutory language does not provide otherwise, the doctrine of corporate veil-piercing applies to LLCs).

${ }^{53}$ See, e.g., 805 Ill. COMP. STAT. 180/30-1, 180/30-20 (2005).

${ }^{54}$ See Stephen R. Looney \& Ronald A. Levitt, Limited Liability Companies Classified as $S$ Corporations-Part II, SN067 ALI-ABA 961 (2008).

${ }^{55} 805$ ILL. COMP. STAT. 5/7.50(c)(3) (2005) (a shareholder may appoint a proxy to vote its shares, including appointing as a proxy a creditor who has extended its credit under terms requiring the proxy appointment. In the event that there is a proxy appointment, its revocability may be limited).
}

Pitt Tax Review | ISSN 1932-1821 (print) 1932-1996 (online) DOI 10.5195/taxreview.2013.16 | http://taxreview.law.pitt.edu 


\section{b. Tax Attributes of an LLC}

An LLC's default tax classification depends on how many owners (members) it has. ${ }^{56}$ For an LLC with only one member, the entity will be disregarded for tax purposes and the owner will be treated as if she were a sole proprietor, causing the business's earnings to be taxed directly to the owner - no entity-level taxation would be imposed because no entity exists for tax purposes. ${ }^{57}$ For an LLC with more than one member, the default classification is a tax partnership. ${ }^{58}$ These classifications apply by default only_pursuant to the so-called "check-the-box" rules, the LLC can elect to be treated as a Subchapter C Corporation for tax purposes. ${ }^{59}$ Once it elects to be taxed as a $\mathrm{C}$ Corporation, it has the option of filing an additional election to be taxed as an S Corporation, assuming the business meets the $\mathrm{S}$ Corporation requirements. ${ }^{60}$ The implications (or lack thereof) for employment taxes of making this series of changes to the LLC's default tax status are discussed below. Here, I assume that the entrepreneur's LLC will be treated as a Subchapter K tax partnership. ${ }^{61}$

\section{i. Improve Basis Treatment Affecting a Future Potential Sale}

Many entrepreneurs starting out may not be concerned about selling their company down the road. However, thinking ahead to such exit strategies is wise and often a key way in which business attorneys can add value for the client. Just as an initial choice-of-entity decision can have a big impact on what kind of investors an entrepreneur can bring into her business and how she can raise capital through the issuance of different

\footnotetext{
${ }^{56}$ See Winchester, supra note 5, at 130-31 (explaining that "[t]he default [tax] rules that apply to a limited liability company depend on whether it has one owner (member) or more than one." Id. at 130.).

${ }^{57}$ See Treas. Reg. § 301.7701-3(b)(1)(ii) (as amended in 2006).

${ }^{58}$ See Treas. Reg. $\S 301.7701-3($ b)(1)(i) (as amended in 2006).

${ }^{59}$ See Treas. Reg. § 301.7701-3(a) (as amended in 2006).

${ }^{60}$ See Winchester, supra note 5, at 130 n.17.

${ }^{61}$ In the event that there is only one owner of the LLC, and it is treated as a disregarded entity, the tax consequences will be similar, although not always identical.
}

Pitt Tax Review | ISSN 1932-1821 (print) 1932-1996 (online) DOI 10.5195/taxreview.2013.16 | http://taxreview.law.pitt.edu 
classes of ownership, ${ }^{62}$ it can also have a substantial impact on the tax consequences an entrepreneur will encounter upon selling her company. As between an S Corporation and LLC, and for a number of reasons including anticipation of a potential sale, how an owner's "outside basis" in a business is calculated can be an important consideration in choosing the appropriate business entity.

A taxpayer's basis in an asset, such as a share of ownership of a business entity, can be understood most easily as the cost that the owner incurred in exchange for her ownership interest in the entity. For example, if the pastry chef and her business partner each contributed $\$ 500$ in cash to the business in exchange for 50 percent of the ownership of their LLC or S Corporation, each person's basis in her ownership interest ("outside basis") would be $\$ 500$. However, if one contributed an antique oven to the business that, since the time of contribution, has appreciated from $\$ 500$ to $\$ 750$, her tax basis would still be $\$ 500$ because that was her out-of-pocket cost at the time of contribution.

Very generally speaking, tax rules that are more liberal in allowing owners' outside bases to be increased are preferable for the entrepreneur as compared to those that are more restrictive. Because taxable gain on property being sold or transferred is calculated by taking the difference between the taxpayer's basis in the property and the fair market value at the time of transfer, a higher basis can reduce the tax imposed on gains. Conversely, if the property is disposed of at a loss for the taxpayer, a higher basis will increase the size of the tax loss, which in some cases may be able to be used to offset taxable income, thus reducing the amount owed to the government by the taxpayer. LLCs and S Corporations, despite having many similarities, have a few key differences as far as calculating owners' outside bases. For an S Corporation, the owner's tax basis in the entity takes into account the out-of-pocket cost that the owner incurred in exchange for her ownership interest and the basis of any loans that the $\mathrm{S}$ Corporation owes to the owner. ${ }^{63}$ The owner's tax basis in the LLC includes both these components, but in contrast also includes the owner's allocable I.A.3.b.

${ }^{62}$ See discussion about capital-raising limitations of S Corporation eligibility rules, supra Part

${ }^{63}$ I.R.C. $§ 1366(d)$.

Pitt Tax Review | ISSN 1932-1821 (print) 1932-1996 (online) DOI 10.5195/taxreview.2013.16 | http://taxreview.law.pitt.edu 
share of all liabilities of the LLC, regardless of whether they are nonrecourse or owed personally by the owner. ${ }^{64}$ Thus, depending on whether the entity has debt or not, the owner of an LLC may have more opportunities increase her outside basis in the business and may pay less tax on future transactions as a result.

\section{ii. Pass-Through of Losses}

As explained above, the income of both LLCs and S Corporations generally passes through and is taxable to the entity's owners. Similarly, if the business generates losses for a taxable period, those too may pass through to the entity's owners and, in some cases, can be used to offset income from other sources. However, there are important limitations on when losses can be used to offset income. Three main "hurdles" must be overcome, ${ }^{65}$ two of which apply equally to S Corporations and LLCs treated as partnerships, and the third, which may operate differentially.

First, losses can be used to offset income only to the extent that an owner actually has amounts "at-risk." An owner's at-risk amount generally includes the amount of money and other property that she has contributed to the business as well as her share of the entity's non-recourse liabilities (i.e., debts for which the owner has guaranteed or is otherwise personally responsible for satisfying). ${ }^{67}$

Second, only certain kinds of losses can offset certain types of income. ${ }^{68}$ The "passive activity loss rule" was adopted in the 1980 s to prevent taxpayers from using losses from passive business ventures to offset (a) income from active businesses or (b) portfolio income (e.g., interest, dividends, gains from stocks and bonds), or, as explained by one commentator, "to stop doctors and others from using losses from real estate and other tax shelters to reduce or eliminate the tax on their professional

\footnotetext{
${ }^{64}$ I.R.C. $§ 752(a)$.

${ }^{65}$ See DRAKE, supra note 20 , at 57-58.

${ }^{66}$ I.R.C. $\S 465(\mathrm{a})(1)$.

${ }^{67}$ I.R.C. $\S 465(\mathrm{a})(2)(\mathrm{A})$.

${ }^{68}$ I.R.C. $\S 469(d)$.
}

Pitt Tax Review | ISSN 1932-1821 (print) 1932-1996 (online) DOI 10.5195/taxreview.2013.16 | http://taxreview.law.pitt.edu 
and business incomes." ${ }^{69}$ Because classification of a business activity as either passive or not passive depends on factors that are likely to deem an involved entrepreneur to be active (she will be a "material participant" because she carries out "regular, continuous and substantial" involvement in the activity $^{70}$ ), it is not clear whether she would be able to use losses from the business to offset other gains. ${ }^{71}$

Third, the losses that pass through to the owner cannot exceed the owner's outside basis in the entity. ${ }^{72}$ This third hurdle is easier to clear if the entity is an LLC taxed under Subchapter K: the owner's outside basis in the LLC may be increased by her share of the debts of the LLC (for an S Corporation, no such additional adjustment can be made). Thus, assuming that the at-risk and passive activity loss hurdles are cleared, an LLC's provision of more "basis for the buck," so to speak, will be a boon for utilizing any losses that the entrepreneur may generate.

\section{iii. Allow Easy Conversion to a Different Type of Entity}

There are a number of ways to convert an LLC taxed as a partnership into a corporation taxable either under Subchapter S or Subchapter C. While an in-depth discussion is available elsewhere, suffice it to say that, from a tax perspective, the consequences can be carefully managed to avoid incurring tax on any gains that have accrued on the LLC's assets. ${ }^{73}$ As we will see later on, easy conversion to a different type of entity confers real option value on entrepreneurs and thus can help them as they navigate the uncertainties of starting up.

\footnotetext{
${ }^{69}$ DRAKE, supra note 20, at 58. Note, however, that "tax" here refers to federal income tax, not self-employment tax, for which doctors and other business owners or self-employed professionals would still be responsible without being offset by losses.

${ }^{70}$ I.R.C. $\S 469(\mathrm{~h})(1)$.

${ }^{71}$ However, non-passive losses should offset active gains.

${ }^{72}$ I.R.C. $\S 704(d)$.

${ }^{73}$ See DRAKE, supra note 20, at 165-67 (discussing four options for converting an entity taxable as a partnership).
}

Pitt Tax Review | ISSN 1932-1821 (print) 1932-1996 (online) DOI 10.5195/taxreview.2013.16 | http://taxreview.law.pitt.edu 


\section{Conclusion: S Corporation Versus LLC}

By focusing on this non-exhaustive subset of factors that typically influences entry-level entrepreneurs choice of entity, this general discussion necessarily leaves out some important aspects that should be considered in light of individual client circumstances. An incomplete list of such factors includes: the availability of tax-advantaged fringe benefits for employees of corporations, ${ }^{74}$ tax-free reorganization potential for corporations, ${ }^{75}$ and flexibility-limiting rules for converting from an $\mathrm{S}$ Corporation to a $\mathrm{C}$ Corporation. $^{76}$

Notwithstanding these additional factors, which may take on particular importance in the case of a particular entrepreneur or business, it is easy to discern a presumption in favor of the LLC taxed in its default classification. It is the more modern, flexible vehicle for new businesses that avoids many of the handcuffs and pitfalls of the S Corporation. But, as the next Part explores, the dominance of the LLC can be threatened, and even toppled, once the employment tax consequences of the S Corporation are taken into consideration.

\section{B. Employment Taxes and the Operation of the Sub-S Shelter}

\section{Employment Tax Basics}

Employment taxes in the U.S. can be thought of as two sides of the same coin-one side taxes earnings from self-employment ("self-

${ }^{74} I d$. at 46 (citing I.R.C. $\$ \S 79$ (group term life insurance), 106 (medical and dental reimbursement plans), 129 (dependent care assistance programs), 132(a)(5) (qualified transportation reimbursement plans)).

${ }^{75}$ After a period of guiding and developing her venture, a small business owner may decide to sell it. One benefit to choosing an S Corporation over an LLC is that only corporations, including S Corporations, are permitted to reorganize tax-free. See I.R.C. $§ 368(\mathrm{~b})$; see also CHRISTIAN \& GRANT, supra note 47, at 29.02. Corporations can combine through merger ("Type A" reorganization), a stockfor-stock transaction ("Type B" reorganization) or a stock-for-assets transaction ("Type C" reorganization) on terms that may eliminate all corporate and shareholder-level taxes. See I.R.C. $\S \S 368(\mathrm{~b}), 368(\mathrm{a})(1)(\mathrm{A})-(\mathrm{C})$. The rationale behind tax-free reorganization is that shareholders are not cashing out; rather, they are maintaining the same investments in the underlying assets, but in a different corporate form. No tax applies because there is no gain or loss in the exchange of stock for stock, and the basis in the new stock is equal to the basis in the old stock. See DRAKE, supra note 20, at 47.

${ }^{76}$ For example, the corporation will not be able to convert back to a C Corporation for at least five years. See I.R.C. $§ 1362(\mathrm{e})(3)$.

Pitt Tax Review | ISSN 1932-1821 (print) 1932-1996 (online)

DOI 10.5195/taxreview.2013.16 | http://taxreview.law.pitt.edu 
employment tax") and the other taxes earnings of an employee within the context of an employer-employee relationship ("payroll tax"). In theory, the amount of employment tax due to the government on a given level of earnings should be equal, but the rules on how taxable earnings are defined in each case can lead to confusion and opportunities for sheltering income.

The self-employment tax mirrors the operation of the better-known payroll tax. Under the payroll tax, employers are responsible for paying half of the employment taxes due in connection with an employee's earnings; the other half of the employment tax liability is paid by the employee via withholding and is deductible from the employee's taxable income. ${ }^{77}$ Similarly, the self-employment tax imposes a tax on "net earnings from self employment" ("NESE"), which is defined as "the gross income derived by an individual from any trade or business carried on by such individual, less the deductions allowed by this subtitle which are attributable to such trade or business ...." ${ }^{78}$ When an entrepreneur is considered self-employedthat is, not an employee of her own business, a distinction which will be discussed further below-the self-employment tax requires her to pay both halves of the total amount that would be due to the government under the payroll tax. However, she can deduct half of the employment taxes she pays from her taxable income. ${ }^{79}$ Thus, the law is designed so that an amount earned as wages by an employee would yield an identical employment tax result as would the same amount earned as NESE by an entrepreneur who is self-employed. ${ }^{80}$

\footnotetext{
${ }^{77}$ I.R.C. $\S \S 3101(\mathrm{a}), 3201(\mathrm{a}), 3211(\mathrm{a})(1)$.
}

${ }^{78}$ I.R.C. $\S 1402$ (a). In the case of the OASDI portion, self-employment income does not include that part of net earnings from self-employment for any tax year in excess of (i) the amount of the contribution and benefit base in effect for the calendar year in which the tax year begins minus (ii) the amount of any wages (i.e., not from self-employment) received by the individual in the same tax year. It also does not include net earnings from self-employment if the total amount for that tax year is less than \$400. See I.R.C. § 1402(b)(1), (2). Also, certain types of passive income derived by an individual from her trade or business are not included in NESE: most income from real estate rents, dividends, interest, capital gains, and other portfolio income, capital gain and other kinds of passive income. See I.R.C. $\S 1402(a)(1)-(3)$.

\footnotetext{
${ }^{79}$ I.R.C. § 164(f).
}

${ }^{80}$ See Winchester, supra note 5, at 132-34 and accompanying notes for a helpful discussion about how the two bases subject to payroll versus self-employment taxes interact- - the definitions are designed so that a person who has both wages from employment and earnings from self-employment does not get taxed twice for OASDI purposes (noting that "The two [regimes] are mutually exclusive so

Pitt Tax Review | ISSN 1932-1821 (print) 1932-1996 (online) DOI 10.5195/taxreview.2013.16 | http://taxreview.law.pitt.edu 
Both the payroll tax and the self-employment tax have two separate components, each of which funds different government insurance programs: old-age, survivors, and disability insurance ("OASDI," commonly known as Social Security) and hospital insurance (commonly known as Medicare). Prior to 2011, and under current law, the OASDI and Medicare rates are 12.4 and 2.9 percent, respectively. ${ }^{81}$ However, these levies apply differently - the OASDI component of the employment tax applies to an individual's earnings up to an inflation-indexed threshold of $\$ 113,700$ in 2013 (the "OASDI cap"), but the Medicare component applies to all earnings, regardless of amount. ${ }^{82}$

As a result of this discontinuity at the OASDI in the rate schedule for the OASDI component, employment taxes are regressive. ${ }^{83}$ As earnings rise and exceed the OASDI cap, the marginal tax rate facing the individual falls by 12.4 percent. Employees or entrepreneurs earning lower amounts may have little hope of exceeding this threshold and seeing their marginal tax rates fall. One study notes that, for 80 percent of individuals who earn self-

that only one set of rules will ever apply to any given dollar of earnings ... the rules ensure that anyone whose income includes both wages from employment and income from self-employment will never be at a disadvantage to someone who does not have income from both sources").

${ }^{81}$ Sections 3111(a) and (b) of the Code specify the amount of employers' liability for employment taxes; Sections 3101(a) and (b) specify the employee's portion of the liability (current rates payable by each of the employer and the employee are $6.2 \%$ for OASDI and $1.45 \%$ for hospital insurance). For the analogous self-employment tax rates, see I.R.C. § 1401(a), (b). Readers should note that OASDI portion of the self-employment and payroll taxes were targets for recession-stimulus initiatives in 2010 through 2012, so applicability and effective rates for these taxes have fluctuated in recent years. For instance, employers could receive an exemption from paying their portion of the OASDI payroll tax for certain individuals hired in 2010. See I.R.C. §3111(d). In the same vein, the Middle Class Tax Relief and Job Creation Act of 2012, Pub. L. No. 112-96, 126 Stat. 156, extended the 2-percentage-point (from $12.4 \%$ to $10.4 \%$ ) employment tax cut through the end of 2012, following earlier legislation that had extended it for only the first two months of 2012. Interestingly, the cut did not apply equally to employees and the self-employed. It reduced the OASDI portion of the selfemployment tax only up to a cap of $\$ 18,350$; there was no similar cap for the payroll tax cut. It is not clear whether Congress intended to penalize the self-employed by limiting the amount of selfemployment earnings eligible for the tax cut.

${ }^{82}$ For current and historic OASDI caps, see Contribution and Benefits Base, U.S. Soc. SEC. ADMIN., http://www.ssa.gov/oact/COLA/cbb.html (last visited Apr. 25, 2013).

${ }^{83}$ See, e.g., Deborah A. Geier, Integrating the Tax Burdens of the Federal Income and Payroll Taxes on Labor Income, 22 VA. TAX REV. 1 (2002) (reviewing a range of statistics showing that the distributional effect of payroll taxes is regressive and calling for an integration of the income tax with the employment tax regime).

Pitt Tax Review | ISSN 1932-1821 (print) 1932-1996 (online)

DOI 10.5195/taxreview.2013.16 | http://taxreview.law.pitt.edu 
employment or wage income, the bite of self-employment or payroll taxes exceeds that of income taxes, often by a substantial amount. ${ }^{84}$

\section{Employment Taxes in a Corporation: The Sub-S Shelter}

At the core of the Sub-S Shelter is the difference in how the earnings of active owners (i.e., those who contribute labor services to their businesses) are treated under the employment tax rules. As Richard Winchester explains, they are designed "in a way that permits a selfemployed individual to have her cake and eat it too." ${ }^{.15}$

Generally speaking, corporations, including those that elect to be treated as S Corporations, can treat owners of the business as employees and can pay them compensation for their labor. ${ }^{86}$ This compensation of the owner-employee will be subject to payroll taxes. So where does the "shelter" come in? Earnings paid to the owner that are not deemed "wages" can be classified as dividends (from a C Corporation) or distributions (from an S Corporation), which are exempt from both payroll taxes and selfemployment taxes. ${ }^{87}$ The result is that income generated by a corporation through a shareholder's active participation in the corporation's business activities can be bifurcated into two parts to minimize the impact of employment taxes. First, part of the corporation's income can be paid out as a "reasonable salary" to the owner-employee, which, as compensation, will be subject to employment (payroll) taxes. ${ }^{88}$ The remaining net income can

${ }^{84}$ See Cong. Budget Office, Economic Stimulus: Evaluating Proposed Changes in Tax Policy, ApProaches to CUtTING Personal TAXes 12 n.7 (2002). See also Drake, supra note 20, at 63 (discussing "that other tax," the self-employment tax, and its typical impact on different types of owners - the "well-heeled" owner rarely feels its bite but it is "structured to punish middle and lowincome workers.").

${ }^{85}$ Winchester, supra note 5, at 134.

${ }^{86}$ For an excellent discussion on this complicated point, see Winchester, supra note 5, at 134-35.

${ }^{87}$ The definition of NESE does not include dividends or distributions, and only wages or compensation is subject to the payroll taxes. See I.R.C. § 1402(a)(2); see also Winchester, supra note 5, at $134 \mathrm{n} .41$.

${ }^{88}$ In determining the corporation's taxable income, such compensation paid to employee-owners would be deductible from earnings. Additionally, the IRS has most frequently challenged taxpayers taking positions that none of their earnings from the business is subject to employment taxes. See, e.g., Spicer Accounting, Inc. v. United States, 918 F.2d 90 (9th Cir. 1990); Radtke v. United States, 712 F. Supp. 143 (E.D. Wis. 1989) (summary judgment for the government), aff'd, 895 F.2d 1196 (7th Cir.

Pitt Tax Review | ISSN 1932-1821 (print) 1932-1996 (online) DOI 10.5195/taxreview.2013.16 | http://taxreview.law.pitt.edu 
then be paid out as the owner's distributive share of the business's earnings. In the context of an S Corporation, such distributions, which can be thought of as similar to dividends paid to shareholders in a regular $\mathrm{C}$ Corporation, are income to the entrepreneur, but, as payments on account of capital, they are subject neither to the payroll tax nor the self-employment tax.

The ability to shelter income from the reach of employment taxes by minimizing the compensation paid out to the entrepreneur by the business comprises the Sub-S Shelter. As a policy matter, the employment tax rules as applied to owner-operated businesses were intended to reflect the economics of the business, but anachronisms in the tax code and regulations have caused these rules to apply in different ways to economically identical arrangements. ${ }^{89}$ The struggle, as will be explained below, is how to appropriately identify income derived from services, which should generally be subject to employment taxes, as distinct from income derived from investments of capital or other returns not connected with the entrepreneur's labor.

\section{Employment Taxes in an LLC}

In contrast to the ability of a corporation to treat an owner as an employee for employment tax purposes, the same cannot be done within an LLC/tax partnership. ${ }^{90}$ Instead of being able to pay a member of an LLC a salary subject to employment taxes while sheltering "non-compensation" distributions, all earnings of an LLC member who is actively involved in her business will be subject to the self-employment tax. This result occurs because NESE is defined to include any "distributive share (whether or not distributed) of income or loss . . from any trade or business carried on by a partnership of which [such individual] is a member."

1990); Nu-Look Design, Inc. v. Comm'r, 85 T.C.M. (CCH) 927, 2003 T.C.M. (RIA) 『 2003-52 (2003), aff'd, 356 F.3d 290 (3d Cir. 2004).

${ }^{89}$ See Winchester, supra note 5, at 135.

${ }^{90}$ See Rev. Rul. 69-184, 1969-1 C.B. 256; see also Schwidetzky, supra note 4, at 787.

${ }^{91}$ I.R.C. $\S 1402(a)(1)$. The definition excludes from NESE items of income from a partnership that are not received in the course of a trade or business, such as rentals of real estate, dividends on stock, interest on bonds or debentures, or capital gains or losses that are not generated in the course of a trade or business (i.e., if the individual's partnership engaged in stock trading, dividends would be included in NESE, but stock investments held by the partnership of an unrelated business would be excluded from NESE). Note that NESE does not include a limited partner's distributive share of income, other than guaranteed payments for services under section 707(c) of the Code. See I.R.C. § 1401(a)(13);

Pitt Tax Review | ISSN 1932-1821 (print) 1932-1996 (online) DOI 10.5195/taxreview.2013.16 | http://taxreview.law.pitt.edu 
silent on how members of LLCs are treated in particular, a plain reading of the statute requires LLC members to count their entire share of the LLC's income as NESE, unless any of it is passive income specifically excluded from the definition of NESE. ${ }^{92}$ The effect of this rule is to prohibit the operation of the Sub-S Shelter in a typical LLC. Actively-involved LLC members cannot bifurcate their income from the LLC between compensation and distributions, because the latter is subject to employment taxes in the same manner as the former.

The only possible exception in the statute to this result - that all income earned by actively-involved members through an LLC or other tax partnership is subject to the self-employment tax-is special treatment afforded to certain "limited partners." Limited partners do not have to include their income from the partnership in NESE so long as the income is not considered a guaranteed payment issued as remuneration for services rendered. ${ }^{93}$ However, the term "limited partner" is not defined in the Code or the Regulations, and has been interpreted as meaning a limited partner under applicable state law. Unfortunately, analogizing between a limited partner, for which there is concrete statutory and regulatory guidance, and a member of an LLC, for which there is not, is fraught with difficulties.

To address some of these difficulties, the IRS published proposed regulations in 1997 that use a "functional approach" to decide whether a member of an LLC should be treated as a limited partner. ${ }^{94}$ The fact that the

Schwidetzky, supra note 4 , at 788 . Schwidetzky points out that, notwithstanding the absence of a definition of a limited partner in the Code or Regulations, "it appears from the legislative history and the plain language of the statute that a state law limited partner is meant." Schwidetzky, supra note 4, at 788.

92 Walter Schwidetzky explains this counter-intuitive result-within an LLC or other tax partnership, NESE includes a broader category of income than that from services-as rooted in the history of the Social Security tax, which originally applied only to wages earned within the employeremployee relationship. See Schwidetzky, supra note 4, at 788-89.

${ }^{93}$ See I.R.C. § 1402(a)(13).

${ }^{94}$ See Definition of Limited Partner for Self-Employment Tax Purposes, Prop. Treas. Reg. $\S 1.1402(a)-2(h), 1997-1$ C.B. 770, 772 [hereinafter Limited Partner]. The 1997 regulations replaced proposed regulations that were issued in 1994 and subsequently withdrawn. The "functional approach" that the Treasury Department introduced in the 1997 proposed regulations has the advantage of applying to all unincorporated organizations taxed as partnerships for federal income tax purposes (GPs, LPs, LLPs, LLLPs, LLCs and newer hybrids), rather than relying on state law designations of whether an owner is considered a "limited" versus a "general" partner, as the (withdrawn) 1994 Proposed

Pitt Tax Review | ISSN 1932-1821 (print) 1932-1996 (online) DOI 10.5195/taxreview.2013.16 | http://taxreview.law.pitt.edu 
regulations are proposed rather than final creates some uncertainty for taxpayers and their advisors, but this uncertainty is mitigated by the duration that the regulations have been in place undisturbed; by all accounts, many practitioners rely on them as if they were final. ${ }^{95}$ To determine whether a member of an LLC can be treated as a limited partner, the functional approach asks whether the member: (1) has personal liability under state law for the obligations of the business, (2) has authority to bind the business in contract, or (3) participates in the business for more than 500 hours during the tax year. ${ }^{96}$

If the LLC member serves any of these three functions, she cannot be considered a "limited partner" for employment tax purposes and all earnings from the LLC must be included in NESE. Almost every activelyinvolved entrepreneur would fall into at least one category. As a result, if the entrepreneur formed an LLC, all earnings from the business would be subject to employment taxes. This "all-in" rule subjecting all LLC earnings of the entrepreneur to employment taxes is, therefore, a key disadvantage as compared to the $\mathrm{S}$ Corporation, which allows bifurcation of earnings.

\section{Are There Any Sub-S Shelter "Workarounds" Available to LLCs?}

In light of this difference in the employment tax implications of operating a business as an LLC versus as an S Corporation, a key question (at least for entrepreneurs and their counsel) is whether there are permissible structures or planning strategies that would allow an LLC to use the Sub-S Shelter. This subsection examines four possible options, but concludes that all of them have serious problems.

Regulations had tried to do. Id. at 770-71; CARTER G. BISHOP \& DANIEL S. KLEINBERGER, Limited LIABILITY COMPANIES ๆ 1.03[2][a][1] (2008).

${ }_{95}$ The 1997 Regulations have been neither finalized nor withdrawn. Following "a flurry of criticism and debate," Section 935 of the Taxpayer Relief Act of 1997, Pub. L. No. 105-34, 111 Stat. 788, prohibited the finalization of these (or similar) Regulations prior to July 1, 1998. See Steven G. Frost \& Sheldon I. Banoff, Square Peg, Meet Black Hole: Uncertain Tax Consequences of Third Generation LLEs, 100 J. TAX'N 326, 338 (2004). One prominent treatise suggests that the Taxpayer Relief Act provisions may have deterred the Service from finalizing the Proposed Regulations. See William S. McKee et al., Federal TaXation of Partnerships \& Partners 9 9.02[5][b][ii] n.616 (4th ed. Supp. 2011); see also Sheryl Stratton, ABA/AICPA Have Legislative Fix for LLC SelfEmployment Tax Problem, 84 TAX NOTES 351 (1999).

${ }^{96}$ See Limited Partner, supra note 94.

Pitt Tax Review | ISSN 1932-1821 (print) 1932-1996 (online)

DOI 10.5195/taxreview.2013.16 | http://taxreview.law.pitt.edu 
First, could the flexibility accorded to LLCs by the check-the-box regulations be exploited to level the playing field in regard to the Sub-S Shelter? An LLC is free to elect out of its default tax classification and into treatment as a corporation taxable under Subchapter C. If it then filed an election to be taxed under Subchapter S, could it bifurcate its income in a manner that would be respected by the IRS? The answer is not clear from the statutory authority because taxable NESE includes "income from any trade or business carried on by a partnership of which [the taxpayer] is a member." ${ }^{, 7}$ Like the term "limited partner," the term "partnership" has been interpreted as referring to a partnership, not for tax purposes, but as a partnership under state law, which is generally construed to include an LLC. ${ }^{98}$ Under this analysis, the election to be treated as an S Corporation for tax purposes would not affect its designation under state law as a partnership, and the self-employment tax would continue to apply to all of the member's earnings from the LLC.

Notwithstanding the complications of state versus tax classifications, however, this "workaround" strategy is unlikely to succeed on the merits because an LLC electing to be treated as a corporation taxable under Subchapter S is functionally equivalent, for purposes of the Subchapter S restrictions, to a state law corporation filing an S election. Thus, she would be subject to the same set of S Corporation restrictions on types of investors and multiple classes of stock that she sought to avoid by forming an LLC instead of an S Corporation. ${ }^{99}$ Moreover, terminating the S Corporation election in the event that the entrepreneur desired to switch classifications would trigger the same tax consequences as if she had started her business as a state law corporation (electing to be taxed as an S Corporation) and then converted to an LLC.

${ }^{97}$ See I.R.C. § 1402(a).

${ }^{98}$ See Schwidetzky, supra note 4, at 788.

${ }^{99}$ See Looney \& Levitt, supra note 54, at 986 (noting that when an LLC elects to be treated as an $\mathrm{S}$ Corporation, "great care must be taken in drafting the operating agreement. Using an operating agreement that is normally used for LLCs that are treated as partnerships for tax purposes may result in the violation of the rule that an S corporation may have only one class of stock issued and outstanding.").

Pitt Tax Review | ISSN 1932-1821 (print) 1932-1996 (online) DOI 10.5195/taxreview.2013.16 | http://taxreview.law.pitt.edu 
Second, could the LLC's flexibility be harnessed to create two classes of interests, one of which could generate passive income not subject to the self-employment tax? In fact, the 1997 Proposed Regulations included provisions that attempted to mitigate the impact of the "all-in" rule for LLCs, perhaps in light of the availability of the Sub-S Shelter. The Regulations did this by offering exceptions that addressed how to appropriately identify income derived from services, which should generally be included in NESE, as distinct from income derived from investments of capital or other returns not connected with the entrepreneur's labor. According to the Proposed Regulations, "[the exceptions] exclude from an individual's net earnings from selfemployment amounts that are demonstrably returns on capital invested in the partnership." 100

In the case of a manager-managed LLC, an exception was included that allowed more than one type of interest to be issued to the same individual under certain circumstances. ${ }^{101}$ Under the 1997 Proposed Regulations, where an LLC member does not qualify as a "limited partner" (i.e., having too much active involvement), bifurcation of an active member's interest in a manager-managed LLC into two interests, only one of which will be NESE, may be permitted so long as: (1) the active member holds more than one class of interest in the manager-managed LLC (i.e., an interest having different rights and obligations that is analogous to multiple classes of stock, discussed above), (2) the member seeking bifurcation has an interest in the LLC that has identical rights and obligations as compared to the interests of other LLC members who do qualify as limited partners under the Proposed Regulation, and (3) the members who qualify as limited partners own a "substantial interest," which is defined in the Regulation as at least 20 percent, in the partnership. ${ }^{102}$ If these conditions are met, the active member (entrepreneur) can shelter from employment taxes the earnings from her distributive share of the LLC that are attributable to the

${ }^{100}$ Limited Partner, supra note 94, at 771.

${ }^{101} I d$. at 771 ("[B]ifurcation of interests is permitted only to the extent the individual's distributive share is identical to the distributive share of partners who qualify as limited partners under the proposed regulations (without regard to the bifurcation rules) and who own a substantial interest in the partnership.").

${ }^{102} I d$.

Pitt Tax Review | ISSN 1932-1821 (print) 1932-1996 (online) DOI 10.5195/taxreview.2013.16 | http://taxreview.law.pitt.edu 
limited partner interest. However, where an entrepreneur lacks initial passive investors, the requirements of the exception are difficult, if not impossible, to meet.

Third, commentators note that the Proposed Regulation contains no family-relatedness rules, so the principal owner of a non-service LLC may be able to bring in a spouse or another family member as a passive partner holding at least twenty percent of the second class of membership interest. At time of release of the Proposed Regulation, some commentators believed that lack of such attribution rules "strongly suggests that the [IRS] will not seek to disregard a Prop. Reg. 1.1402(a)-2(h)(2) partner for purposes of the substantial passive partner rule merely because she is a spouse or other relative of an active partner relying on that [exception]." ${ }^{103}$ However, there has been no guidance or rulings issued by the Service or courts since 1997 to shed light on this question. Therefore, its chances for success are speculative at best.

A last workaround option would be to seek out a twenty-percent LLC member who qualifies as a bona fide limited partner under the Proposed Regulations. To the extent that bringing on a substantial passive owner comports with the business's overall strategy, this is a promising avenue to consider. However, favorable employment tax treatment for active members will then depend on keeping this passive partner at no less than a twenty percent ownership level. For entrepreneurs not otherwise considering the inclusion of passive investors in their business, this strategy puts the tax "cart" before the business "horse."

This Part aims to have made two observations about choice-of-entity for entry-level entrepreneurs. First, ignoring the impact of employment taxes, the LLC is generally a more flexible and advantageous vehicle as compared to a corporation (the S Corporation in particular) for the typical entry-level entrepreneur. Second, when the effect of the Sub-S Shelter is taken into account, the S Corporation offers employment tax advantages that cannot be countered by the LLC. The next Part of this Article argues that, because employment tax savings of the Sub-S Shelter are likely to be hypersalient for entry-level entrepreneurs, the choice of entity decision will

\footnotetext{
${ }^{103}$ John M. Cunningham, LLC Owners Can Avoid Self-Employment Tax Under New Prop. Regs., 58 TAX’N FOR ACCT. 196 (1997).
}

Pitt Tax Review | ISSN 1932-1821 (print) 1932-1996 (online) DOI 10.5195/taxreview.2013.16 | http://taxreview.law.pitt.edu 
be more complicated for this cohort as compared to better-resourced entrepreneurs. This increased complexity imposes disproportionate costs on those least able to shoulder the burden, and may result in behavioral distortions as entry-level entrepreneurs gravitate towards the S Corporation and away from the LLC, to the detriment of their businesses' future growth prospects.

\section{THE REgRESSIVE HyPERSALIENCE OF THE SUB-S SHELTER AND ITS IMPACTS}

The potential savings from the Sub-S Shelter are likely to be particularly prominent, or hypersalient, in the choice-of-entity deliberations of entry-level entrepreneurs as compared to non-entry-level entrepreneurs. The first subpart locates the source of this hypersalience in three characteristics that are typical of entry-level entrepreneurs. The second subpart addresses the distributional consequences of the hypersalience of the Sub-S Shelter for entry-level entrepreneurs, finding that it is regressive in equity terms.

\section{A. The Sub-S Shelter Is Hypersalient for Entry-Level Entrepreneurs}

The concept of the salience of a tax is quite simple. It refers to how the presentation, or the prominence, of a tax affects (or does not affect) a taxpayer's response to a tax. In the legal context, Deborah Schenk posits salience as a cognitive bias that taxpayers employ to help manage tax complexity-a "heuristic," or a mental shortcut, that helps taxpayers navigate complicated decisions. ${ }^{104}$ She explains that "[m]ore complex taxes create more opportunities for salience to be an issue." ${ }^{105}$ David Gamage and Darien Shanske point out that tax salience is inextricably linked to the ability of taxpayers to understand the costs of taxation, because "tax salience would be meaningless in a world of complete information in which taxpayers had unlimited time and resources and were not subject to

${ }^{104}$ See Deborah H. Schenk, Exploiting the Salience Bias in Designing Taxes, 28 YALE J. REG. 253, 261-63 (2011).

${ }^{105} I d$. at 263 .

Pitt Tax Review | ISSN 1932-1821 (print) 1932-1996 (online) DOI 10.5195/taxreview.2013.16 | http://taxreview.law.pitt.edu 
cognitive biases." 106 Thus, salience is likely to play a role where taxpayers need to deliberate about, or otherwise calculate, their tax outcomes. And, in connecting tax salience to tax benefits as well as tax burdens, Lillian Faulhauber has argued that where a tax subsidy or benefit is salient, but the restrictions limiting that benefit are less salient, the result is "hypersalience"-taxpayers may over-estimate their tax benefits as compared to the burdens of the restriction. As a result, taxpayer's behavior - their responsiveness to tax-will be distorted. ${ }^{107}$

I leverage these scholars' work on tax salience to propose, in the context of the Sub-S Shelter, that the hypersalience of a tax (benefit) to taxpayers may vary depending on the taxpayer's characteristics, underlying preferences, or cognitive biases. This phenomenon - that the salience of a tax can vary across different types of taxpayers-was documented empirically by economists Jacob Goldin and Tatiana Homonoff, who show that the salience of a cigarette excise tax varies by income. ${ }^{108}$ I suggest that a similar salience dynamic is taking place with respect to the Sub-S Shelter - the preferences and biases and the restrictions on the benefits to be less salient of entry-level entrepreneurs may cause the benefits of the Sub-S Shelter to be more salient to them than to more established or betterresourced entrepreneurs. Hypersalience of the Sub-S Shelter is the result of such a dynamic.

There are three characteristics common to most entry-level entrepreneurs that make the Sub-S Shelter hypersalient. Entry-level entrepreneurs have lower expected earnings as compared to non-entry-level entrepreneurs, and they also may have a higher "personal discount rate" (they value near-in-time earnings highly). These two characteristics interact with a third characteristic, the cognitive bias of over-optimism that has been found to be common in entrepreneurs. Over-optimism makes the potential

\footnotetext{
${ }^{106}$ See Gamage \& Shanske, supra note 16, at 23 (noting that “" tax salience' refers to the extent to which taxpayers account for the costs imposed by taxation when the taxpayers make decisions or judgments.").

${ }^{107}$ See Faulhaber, supra note 7, at 1316 (noting that "[a]n aspect of taxation that has heretofore not been discussed in detail is that it is possible for taxpayers to overestimate how a part of the tax system will affect them.").

${ }^{108}$ See Jacob Goldin \& Tatiana Homonoff, Smoke Gets in Your Eyes: Cigarette Tax Salience and Regressivity, 5 AM. ECON. J.: ECON. POL’Y 302 (2013).
}

Pitt Tax Review | ISSN 1932-1821 (print) 1932-1996 (online) DOI 10.5195/taxreview.2013.16 | http://taxreview.law.pitt.edu 
tax savings of the Sub-S Shelter especially likely to be salient for entrylevel entrepreneurs.

\section{Entry-Level Entrepreneurs Have Lower Expected Earnings}

First, I observe that the average entry-level entrepreneur will have lower expected earnings as compared to the average non-entry-level entrepreneur. By definition, the entry-level entrepreneur is starting her business with few resources, and is likely interested in entrepreneurship as a means of subsistence or support to improve on the insecurity of traditional employment. Her opportunity costs of time and labor will therefore be low, from which we can infer that her expected earnings from her business will be lower, on average, than non-entry-level entrepreneurs. ${ }^{109}$ Non-entrylevel entrepreneurs who have greater resources - including human capitalat their disposal will, on average, bear higher opportunity costs from leaving their existing positions in the workforce. For example, a computer engineer with a graduate degree and substantial savings may decide to strike out on her own to realize her dreams of founding a start-up. However, in order for this decision to be worthwhile, her long-run expected earnings are likely to be substantially higher than those of the entry-level entrepreneur who is simply trying to improve on her alternatives. Why do lower expected earnings make the benefit of the Sub-S Shelter more salient? As we will see by comparing Tables 1 and 2, the tax savings will be more substantial as a proportion of earnings for the entry-level entrepreneur.

\section{Entry-Level Entrepreneurs Have High Personal Discount Rates}

Second, by virtue of entry-level entrepreneurs, lack of ready access to credit (or stockpiles of cash), they are likely to have higher personal discount rates than other less resource-constrained entrepreneurs. Put simply, a "discount rate" is the rate at which the value of something erodes over time. Discount rates are often described as representing the "time value" of money. The notion of an individual's "personal discount rate"

${ }^{109}$ Of course, individual entrepreneurs may have unusually high earnings. But, in expectation, average earnings will be lower than better-resourced entrepreneurs with higher opportunity costs.

Pitt Tax Review | ISSN 1932-1821 (print) 1932-1996 (online) DOI 10.5195/taxreview.2013.16 | http://taxreview.law.pitt.edu 
speaks to her preferences for money (or some other good) over time. ${ }^{110}$ Consistent with the idea that rational actors prefer a fixed sum today more than the same fixed sum tomorrow, the discount rate tells us by how much.

Economists have documented that internal discount rates vary across different contexts, societies, and individuals. ${ }^{111}$ For the purposes of the discussion here, all that is necessary is to assume that the entry-level entrepreneur's access to cash and credit is constrained, and that the entrepreneur needs resources in the start-up phase of the business in order to get to the income-earning phase of the business. The entry-level entrepreneurs' upfront need for liquid resources when starting the business translates into having a high internal discount rate - the value placed on having cash or other assets to invest in the business sooner rather than later will be high. Otherwise, the business may not get off the ground at all. Therefore, business structures that offer near-in-time cost savings, particularly savings against cash outlays such as taxes due are likely to be particularly attractive to entry-level entrepreneurs. Because the Sub-S Shelter promises to deliver tax savings as soon as the entrepreneur begins earning in excess of a "reasonable salary," these (possible) near-in-time benefits will be highly-valued by a cash-constrained entrepreneur, especially as compared to the more speculative upside of forming a more flexible LLC.

\section{Entry-Level Entrepreneurs Are Over-Optimistic}

In addition to these two characteristics of lower expected earnings and higher discount rates, psychologists and other social scientists have found robust evidence that individuals tend to be overly optimistic when predicting future life outcomes. ${ }^{112}$ There is further evidence that

${ }^{110}$ See John T. Warner \& Saul Pleeter, The Personal Discount Rate: Evidence from Military Downsizing Programs, 91 AM. ECON. REV. 33, 33 (2001) (defining the "personal discount rate" as "[t]he rate at which individuals trade current for future dollars ....").

${ }^{111}$ See, e.g., Glenn W. Harrison et al., Estimating Individual Discount Rates in Denmark: A Field Experiment, 92 AM. ECON. REV. 1606 (2002) (finding using experimental results on a Danish population that discount rates vary significantly with respect to several socio-demographic variables).

112 See, e.g., Shelley E. Taylor \& Jonathon D. Brown, Illusion and Well-Being: A Social Psychological Perspective on Mental Health, 103 Psychol. Bull. 193 (1988); Neil D. Weinstein, Unrealistic Optimism About Future Life Events, 39 J. PersonAlity \& Soc. Psychol. 806 (1980). See generally Amos Tversky \& Daniel Kahneman, Judgments Under Uncertainty: Heuristics and Biases, 185 SCI. 1124 (1974).

Pitt Tax Review | ISSN 1932-1821 (print) 1932-1996 (online) DOI 10.5195/taxreview.2013.16 | http://taxreview.law.pitt.edu 
entrepreneurs in particular tend to display a bias towards optimism in projecting the likelihood of success of their nascent ventures. ${ }^{113}$ I argue that, in the context of entry-level entrepreneurs, this bias may cause overoptimism not only about whether the nascent venture will actually open for business and begin generating revenues, but also about how quickly the business will generate sufficient earnings to pay the entrepreneur a substantial salary.

As we saw above, for the Sub-S Shelter to be effective in reducing employment taxes, the entrepreneur must pay herself in excess of a "reasonable salary" for employment tax purposes. ${ }^{114}$ Even if this reasonable salary is fairly low, it still must be something substantially more than zero to avoid attracting scrutiny from the IRS. ${ }^{115}$ But statistics on new business survival indicate that success, or at least staying open for more than a few years, is a minority outcome. ${ }^{116}$ Moreover, having low or no startup capital is a robust "risk factor" for a new business. ${ }^{117}$ These general observations indicate that the very fact that an entrepreneur falls into the category of being "entry-level" (i.e., has poor access to startup cash or credit) means that the so-called optimism bias may be at play-the entrepreneur is launching her business despite the high likelihood of failure for businesses with similar startup profiles. Similarly, an entry-level entrepreneur is likely to be overly optimistic in predicting how quickly her business will generate sufficient revenues to allow her to pay herself something above a

${ }^{113}$ See Cassar, supra note 13, at 822-23 (noting that entrepreneurs' expectations are usually assumed to be "rational" (not biased); investigating whether there is evidence of overoptimism).

${ }^{114}$ See supra note 88 and accompanying text.

${ }^{115}$ In the case of a pastry chef, the salary range appears to be between $\$ 20,000$ and $\$ 60,000$, depending, presumably, on experience and local market conditions. See Pastry Chef Salary, PAYSCALE, http://www.payscale.com/research/US/Job=Pastry_Chef/Salary\#by_Industry.

${ }^{116}$ See generally Brian Headd, Redefining Business Success: Distinguishing Between Closure and Failure, 21 SMALl BUS. ECON. 51 (2003).

${ }^{117}$ See Jim Everett \& John Watson, Small Business Failure and External Risk Factors, 11 SMALL Bus. ECON. 371 (1998) (finding evidence linking low or zero startup capital to higher closure rates). See also Headd, supra note 116, at 59 (finding that " $[\mathrm{t}]$ he factors leading to survival were similar to those found in other studies. Size and such resource indicators as having employees, a good amount of starting capital, and an educated owner correlated with survival.”). However, Headd made the surprising finding that zero startup capital increased the propensity for entrepreneurs to consider their business closure a "success"; he hypothesized that low initial expectations may be the cause. Id. at 56.

Pitt Tax Review | ISSN 1932-1821 (print) 1932-1996 (online) DOI 10.5195/taxreview.2013.16 | http://taxreview.law.pitt.edu 
reasonable salary, thus making a key "restriction" on using the Sub-S Shelter seem less prominent and contributing to the shelter's hypersalience.

4. The Structure of the Sub-S Shelter Interacts with Characteristics Typical of Entry-Level Entrepreneurs to Make Its Benefits Hypersalient

The structure of the Sub-S Shelter interacts with three characteristics of entry-level entrepreneurs-low expected earnings, high personal discount rates, and over-optimism - to increase the likelihood that the benefits of the shelter will be particularly salient and the restrictions on those benefits will be less salient for this group. First, the savings from the Sub-S Shelter are highest where an entrepreneur's earnings are maximally sheltered. This happens when earnings are sheltered not just from the 2.9 percent Medicare portion of employment taxes, which has no maximum amount to which it applies, but also from the 12.4 percent OASDI portion. But, because the OASDI portion has a "cap" that is set at about $\$ 113,000$, the value of the shelter as a percentage of an entrepreneur's gross earnings will be highest where an entrepreneur expects to have annual gross earnings that are less than the OASDI cap. This relationship is likely to increase the salience of the tax savings shelter for entry-level entrepreneurs expecting to earn modest amounts, as the ratio of tax savings to earnings is longer.

The second and third attributes work together to create hypersalience of the Sub-S Shelter for entry-level entrepreneurs. Overly optimistic projections about how quickly the business will be able to pay the entrepreneur something more than a reasonable salary, combined with the entrepreneur's high discount rate have the effect of inflating the value to the entrepreneur of the shelter's potential tax savings.

The following tables provide an illustration of how employment tax savings can vary across time in an S Corporation (using the Sub-S Shelter for all income over a "reasonable salary" of $\$ 35,000$ ) as compared to an LLC. Table 1 lays out the outcomes for an entry-level entrepreneur who expects that she will be able to start paying herself a salary in year two and will exceed her "reasonable salary" in year three, thus allowing the Sub-S Shelter to "work" to save employment taxes. Table 2 shows the corresponding outcomes for a non-entry-level entrepreneur who will earn substantially more. I assume that this cohort is distinguished by its better access to resources, i.e., the non-entry level entrepreneur has sufficient start-up capital to weather a few years of losses during which she effectively contributes capital to the business by working without pay.

Pitt Tax Review | ISSN 1932-1821 (print) 1932-1996 (online) DOI 10.5195/taxreview.2013.16 | http://taxreview.law.pitt.edu 


\section{4 | Pittsburgh Tax Review | Vol. 102013}

However, I assume that she also expects to recover those amounts through higher future earnings.

Table 1: Entry-Level Entrepreneur Scenario

\begin{tabular}{|c|c|c|c|c|c|c|c|c|c|c|c|c|c|}
\hline \multirow[t]{2}{*}{ Year } & \multirow{2}{*}{\multicolumn{2}{|c|}{$\begin{array}{c}\text { Gross } \\
\text { Earnings }\end{array}$}} & \multicolumn{4}{|c|}{$\begin{array}{l}\text { Earnings Subject to } \\
\text { Employment Taxes }\end{array}$} & \multicolumn{4}{|c|}{ Employment Tax Liability } & \multicolumn{2}{|c|}{$\begin{array}{c}\text { Tax } \\
\text { "Savings" } \\
\text { of Sub S } \\
\text { Shelter } \\
\end{array}$} & \multirow[t]{2}{*}{$\begin{array}{c}\text { Tax Savings } \\
\text { as } \% \text { of Gross } \\
\text { earnings } \\
\end{array}$} \\
\hline & & & & S Corp & & $\mathrm{LLC}$ & & orp & & LLC & & & \\
\hline 1 & $\$$ & $(10,000)$ & $\$$ & - & $\$$ & - & $\$$ & - & $\$$ & - & $\$$ & - & $0 \%$ \\
\hline 2 & $\$$ & 35,000 & $\$$ & 35,000 & $\$$ & 35,000 & $\$$ & 5,355 & $\$$ & 5,355 & $\$$ & - & $0 \%$ \\
\hline 3 & $\$$ & 50,000 & $\$$ & 35,000 & $\$$ & 50,000 & $\$$ & 5,355 & $\$$ & 7,650 & $\$$ & 2,295 & $5 \%$ \\
\hline 4 & $\$$ & 55,000 & $\$$ & 35,000 & $\$$ & 55,000 & $\$$ & 5,355 & $\$$ & 8,415 & $\$$ & 3,060 & $6 \%$ \\
\hline 5 & $\$$ & 60,000 & $\$$ & 35,000 & $\$$ & 60,000 & $\$$ & 5,355 & $\$$ & 9,180 & $\$$ & 3,825 & $6 \%$ \\
\hline 6 & $\$$ & 65,000 & $\$$ & 35,000 & $\$$ & 65,000 & $\$$ & 5,355 & $\$$ & 9,945 & $\$$ & 4,590 & $7 \%$ \\
\hline 7 & $\$$ & 70,000 & $\$$ & 35,000 & $\$$ & 70,000 & $\$$ & 5,355 & $\$$ & 10,710 & $\$$ & 5,355 & $8 \%$ \\
\hline 8 & $\$$ & 70,000 & $\$$ & 35,000 & $\$$ & 70,000 & $\$$ & 5,355 & $\$$ & 10,710 & $\$$ & 5,355 & $8 \%$ \\
\hline 9 & $\$$ & 70,000 & $\$$ & 35,000 & $\$$ & 70,000 & $\$$ & 5,355 & $\$$ & 10,710 & $\$$ & 5,355 & $8 \%$ \\
\hline 10 & $\$$ & 70,000 & $\$$ & 35,000 & $\$$ & 70,000 & $\$$ & 5,355 & $\$$ & 10,710 & $\$$ & 5,355 & $8 \%$ \\
\hline
\end{tabular}

Notes: Employment taxes calculated on relevant earnings at a rate of 15.3 percent. In the market context of an entry-level entrepreneur, "reasonable salary" is assumed to be $\$ 35,000$.

In Table 1, an entry-level entrepreneur who declares a "reasonable salary" of $\$ 35,000$ sees the amount of tax savings generated by the $\mathrm{S}$ Corporation as compared to the LLC steadily increasing — at significant percentages - as the entrepreneur's earnings climb towards the OASDI cap. ${ }^{118}$ It is easy to imagine that the liquidity-constrained entrepreneur with modest expectations of earnings from her business might jump at the opportunity to save between five and ten percent of her gross earnings using the Sub-S Shelter. Moreover, if the entrepreneur begins generating earnings above the reasonable salary early in the life of the business, these savings from the shelter come early and are rendered even more attractive by a high personal discount rate. All of these factors reinforce one another to increase the likelihood that the proffered tax savings of the shelter will be hypersalient for an entry-level entrepreneur.

${ }^{118}$ Note that Table 2 supposes that the earnings level out at $\$ 70,000$, but tax savings would increase linearly so long as gross earnings were below the OASDI cap.

Pitt Tax Review | ISSN 1932-1821 (print) 1932-1996 (online) DOI 10.5195/taxreview.2013.16 | http://taxreview.law.pitt.edu 
Table 2: Non-Entry Level Entrepreneur Scenario

\begin{tabular}{|c|c|c|c|c|c|c|c|c|c|c|c|c|}
\hline \multirow[t]{3}{*}{ Year } & \multirow[t]{3}{*}{$\begin{array}{c}\text { Gross } \\
\text { earnings }\end{array}$} & \multicolumn{5}{|c|}{ Earnings subject to employment taxes } & \multicolumn{3}{|c|}{$\begin{array}{l}\text { Employment tax } \\
\text { liability }\end{array}$} & \multicolumn{2}{|c|}{$\begin{array}{c}\text { Tax } \\
\text { "Savings" } \\
\text { of Sub S } \\
\text { Shelter } \\
\end{array}$} & $\begin{array}{c}\text { Tax } \\
\text { Savings as } \\
\% \text { of } \\
\text { Gross } \\
\text { earnings } \\
\end{array}$ \\
\hline & & S Corp & & & $\mathrm{LC}$ & & & S Corp & LLC & & & \\
\hline & & & & & & & & & & & & \\
\hline 1 & $\$(50,000)$ & - & $\$$ & - & $\$$ & - & $\$$ & - & $\$$ & $\$$ & & $0 \%$ \\
\hline 2 & $\$(30,000)$ & $\$$ & $\$$ & - & $\$$ & - & $\$$ & - & $\$$ & $\$$ & - & $0 \%$ \\
\hline 3 & $\$(20,000)$ & $\$$ & $\$$ & - & $\$$ & - & $\$$ & - & $\$$ & $\$$ & - & $0 \%$ \\
\hline 4 & $\$ \quad-$ & $\$$ & $\$$ & - & $\$$ & - & $\$$ & - & $\$$ & $\$$ & - & $0 \%$ \\
\hline 5 & $\$ 50,000$ & $\$ 50,000$ & $\$$ & 50,000 & $\$$ & 50,000 & & 7,650 & $\$ 7,650$ & $\$$ & - & $0 \%$ \\
\hline 6 & $\$ 150,000$ & $\$ 70,000$ & $\$$ & 110,100 & $\$$ & 150,000 & & 10,710 & $\$ 18,002$ & $\$$ & 7,292 & $5 \%$ \\
\hline 7 & $\$ 150,000$ & $\$ 70,000$ & $\$$ & 110,100 & $\$$ & 150,000 & & 10,710 & $\$ 18,002$ & $\$$ & 7,292 & $5 \%$ \\
\hline 8 & $\$ 150,000$ & $\$ 70,000$ & $\$$ & 110,100 & $\$$ & 150,000 & & 10,710 & $\$ 18,002$ & $\$$ & 7,292 & $5 \%$ \\
\hline 9 & $\$ 150,000$ & $\$ 70,000$ & $\$$ & 110,100 & $\$$ & 150,000 & & 10,710 & $\$ 18,002$ & $\$$ & 7,292 & $5 \%$ \\
\hline 10 & $\$ 150,000$ & $\$ 70,000$ & $\$$ & 110,100 & $\$$ & 150,000 & & 10,710 & $\$ 18,002$ & $\$$ & 7,292 & $5 \%$ \\
\hline
\end{tabular}

Notes: Employment taxes calculated on relevant earnings as noted above (statutory cap for OASDI tax in 2012 was $\$ 110,100$; no cap for Medicare portion of employment taxes). In the market context of a non-entry-level entrepreneur, please assume that a "reasonable salary" is set at to be $\$ 70,000$.

Table 2, on the other hand, shows that once the non-entry-level entrepreneur starts earning income that is subject to employment taxes, the proportion of earnings represented by the tax savings from the Sub-S Shelter is lower ( 5 percent in the example used, as opposed to between 6 to 8 percent for the lower-income entrepreneur), so long as the earnings are above the OASDI cap. For this same reason, the savings remain constant over time. Although these savings are sizable in terms of dollars, they are farther away in time and do not grow as percentage of income.

None of these factors conclusively show that the non-entry level entrepreneur will find the tax savings from the Sub-S Shelter less salient than the entry-level entrepreneur. However, if we further suppose that the more experienced, non-entry-level entrepreneur possesses a greater appreciation for the costs of using the shelter-the constraints that operating as an S Corporation place on the business - then, by comparison, the cash-strapped novice entrepreneur facing lower expected earnings and a high discount rate will find the restrictions on the benefits of the tax shelter to be relatively less salient.

Pitt Tax Review | ISSN 1932-1821 (print) 1932-1996 (online) DOI 10.5195/taxreview.2013.16 | http://taxreview.law.pitt.edu 


\section{B. The Hypersalience of the Sub-S Shelter Has Regressive Equity Implications}

This second subpart describes the consequences of this hypersalience of the Sub-S Shelter for entry-level entrepreneurs.

1. The Sub-S Shelter Increases Complexity for Entry-Level Entrepreneurs as Compared to Other Entrepreneurs

As emphasized in Part $\mathrm{I}$, the choice-of-entity decision entails substantial complexity costs for any entrepreneur, but the hypersalience of the Sub-S Shelter disproportionately increases complexity for entry-level entrepreneurs. Complexity costs include costs incurred by the entrepreneur associated with learning about the different entity candidates, understanding each type of tax treatment available, identifying the non-tax differences of the two choices, figuring out which factors are of primary importance to her, and forecasting the probable impact of taking advantage of, or foregoing, any one of them ("deliberation costs").

These deliberation costs will be present whether or not the entrepreneur is represented by counsel-even in a scenario where an attorney recommends one of the two choices and explains that decision very briefly, the cost of hiring a legal advisor can be thought of as part of the deliberation costs of making the entity decision. Furthermore, anecdotal evidence suggests that one of the primary reasons entrepreneurs, and entrylevel entrepreneurs in particular, seek legal advice is to navigate the complexities of choice-of-entity. ${ }^{119}$

Part I shows that the merits of the decision between the S Corporation and the LLC are fairly straightforward when the Sub-S Shelter is left aside. For non-entry-level entrepreneurs, the decision is likely to remain straightforward because the Sub-S Shelter will be less salient-the shelter may be less likely to be a compelling factor in the choice-of-entity decision due to non-entry level entrepreneurs' higher expected earnings and lower personal discount rate. As a result, this cohort will be able to proceed with

\footnotetext{
${ }^{119}$ These anecdotes stem from the author's experience as an attorney in a small business clinic. The number one reason that lower-income entrepreneurs called the clinic to seek assistance was in forming an entity. Future work aims to substantiate this anecdote over a more systematic sample of respondents.
}

Pitt Tax Review | ISSN 1932-1821 (print) 1932-1996 (online) DOI 10.5195/taxreview.2013.16 | http://taxreview.law.pitt.edu 
the choice-of-entity decision without facing the same kind of deliberation costs as the entry-level entrepreneur. In contrast, for entry-level entrepreneurs who have lower expected earnings, higher discount rates and tend to be overoptimistic, the savings of the Sub-S Shelter are hypersalient, which can result in two alternatives - the LLC and the S Corporationseeming more evenly matched. This makes the choice-of-entity decision more complicated for entry-level entrepreneurs. These entrepreneurs must bear increased costs of deliberating, and the costs are regressive because entry-level entrepreneurs have fewer resources to diffuse them.

\section{The Sub-S Shelter "Call Option" Distorts the Entity Decision}

The entrepreneur's choice to avail herself of the Sub-S Shelter can be viewed as a call option. Characterizing the choice as an option in the financial sense is helpful in two ways. First, for the purposes of this subsection, it illustrates how the entity decisions of entry-level entrepreneurs are likely to be distorted by the incentives presented by the shelter. Second, viewing the choice to use the Sub-S Shelter as an option helps map out a path for modest reforms through government efforts to adjust the salience of the shelter for entry-level entrepreneurs.

Buying an option is, most generally, "paying money today for the opportunity to make a further investment" in the future. ${ }^{120}$ While many choices are often referred to colloquially as "options," true options only come into being where there is uncertainty about the future (no one would purchase an option today to trade on fixed terms in the future if that future was already determined with certainty). Therefore, viewing the entrepreneur's choice-of-entity decision as an option is useful only to the extent that the value of the choice-forming the business as an $\mathrm{S}$ Corporation versus an LLC - is uncertain for the entrepreneur. As we have seen, for the entry-level entrepreneur, this is almost always the case. The relative merits of each type of entity are largely future-contingent, which is part of what makes the choice-of-entity decision so complicated. Will the business need to bring in new owners investing through an entity rather than as individuals? Will it need to issue more than one class of stock? What are the expected earnings of the business? For an entrepreneur just

\footnotetext{
${ }^{120}$ Richard A. Brealey et Al., Principles of Corporate FinanCe 564 (9th ed. 2008) (“"[p]ut another way, the company is acquiring growth opportunities.").
}

Pitt Tax Review | ISSN 1932-1821 (print) 1932-1996 (online) DOI 10.5195/taxreview.2013.16 | http://taxreview.law.pitt.edu 
starting out on the path of launching her business, these questions can be daunting and the answers little better than educated guesses.

Accordingly, the entrepreneur's choice to avail herself of the Sub-S Shelter can be characterized as an option. More specifically, the Sub-S Shelter can be thought of as a "call" option because it gives the entrepreneur the right to buy (claim) the value of limiting the amount of her earnings that are subject to employment taxes. There are two stages through which the life of the call option progresses: at stage one, the entrepreneur decides whether to purchase the call option and at stage two, the entrepreneur who has purchased the option decides whether or not to exercise it.

At stage one, the call option is sold ("written") by the government to ("in favor of") the taxpayer on an underlying tax asset. ${ }^{121}$ The observable result is that the entrepreneur forms an S Corporation. The underlying tax asset that is the subject of the option represents the expected net present value of the Sub-S Shelter to the entrepreneur, which is uncertain for the reasons discussed above. Additionally, the reason that the expected present value of the Sub-S Shelter should be thought of on a "net" basis is because the entrepreneur's valuation of the asset must take into account the costs of the Sub-S Shelter, as well as the possible benefits. Therefore, when weighing the value of the underlying asset, the entrepreneur must estimate the opportunity cost of using the shelter-i.e., the foregone flexibility of the LLC. In some situations, the opportunity cost of choosing an S Corporation may be very high, such as if the entrepreneur expects to quickly recruit sophisticated investors who will likely be reluctant to invest in the business as individuals. In others, such as when the entrepreneur has no need or desire to giving up any of her ownership stake in the business, the opportunity cost of choosing an S Corporation may be minimal because the restrictions associated with Subchapter S will not constrain her. A high or low opportunity cost of using the Sub-S Shelter will reduce or increase the value of the option's underlying tax asset.

The Sub-S Shelter call option sold at stage one has a purchase price, which can be represented as the net costs incurred by the entrepreneur to (i) deliberate about whether to buy the option (with or without the help of a

\footnotetext{
${ }^{121} I d$. at 576.
}

Pitt Tax Review | ISSN 1932-1821 (print) 1932-1996 (online) DOI 10.5195/taxreview.2013.16 | http://taxreview.law.pitt.edu 
lawyer) and (ii) to form an S Corporation entity so that the call option can be exercised. ${ }^{122}$ These costs are evaluated on a "net" basis in that they take into account the costs that the entrepreneur would face in a choice-of-entity world without the Sub-S Shelter. Taking the two components of the option's purchase price in reverse order, the net costs of forming an entity are probably zero - even without the Sub-S Shelter, the entrepreneur would need to form some sort of limited liability entity, and, leaving filing fees aside, the costs of forming an LLC are approximately the same as the costs of forming an S Corporation. But, concerning the first component, the Sub$\mathrm{S}$ Shelter is likely to complicate the entry-level entrepreneur's entity decision, and these added deliberation costs represent the call option's purchase price. These costs may be substantial for entry-level entrepreneurs for whom the shelter is hypersalient. ${ }^{123}$

At stage two of the option analysis, the entrepreneur who has purchased the option to shelter her earnings by forming an S Corporation at stage one, later considers whether to exercise the option by using the Sub-S Shelter to limit her employment taxes. The exercise price is what it costs the entrepreneur to deploy the Sub-S Shelter once she is in the position to do so. That is, once she has formed the S Corporation, commenced operations, some financial certainty about her future, and is filing her tax return for the business, the exercise price can be thought of as the costs of bifurcating her income between taxable compensation and sheltered $\mathrm{S}$ Corporation distributions. It may include hiring an accountant who is familiar with the bifurcation strategy and can properly document the entrepreneur's tax positions, among other matters. The exercise price is paid on the date the option is exercised, which must be on or before the option's maturity. Here, the maturity of the option is the deadline for making the $\mathrm{S}$ election. ${ }^{124}$ The entrepreneur who has purchased the call

\footnotetext{
${ }^{122}$ While these initial costs of availing oneself of the Sub-S Shelter are cast as the "purchase price," another important cost of the Shelter-the potential opportunity cost, or the price of the forgone flexibility of an alternative entity such as the LLC - motivates the discussion below about real options. Designing the choice-of-entity decision as a real option avoids the potentially high opportunity cost of choosing the Sub-S Shelter.

${ }^{123}$ See infra Part III.A.

${ }^{124}$ See Instructions for Form 2553, supra note 28. The deadline is no more than two months and fifteen days after the start of the tax year in which the election is to take effect.
}

Pitt Tax Review | ISSN 1932-1821 (print) 1932-1996 (online) DOI 10.5195/taxreview.2013.16 | http://taxreview.law.pitt.edu 
option at stage one will exercise it at stage two if it is "in the money"- that is, if the underlying asset value exceeds the option's exercise price.

Given this anatomy of the Sub-S Shelter call option, what determines its value and, therefore, the likelihood that a given entrepreneur will buy the call option? There are a number of variables that increase or decrease the call option's value as they fluctuate (assuming that other variables are held constant). First, the value of a call option increases when the price of the underlying asset increases. ${ }^{125}$ Second, the value of a call option increases as the volatility of the price of underlying asset increases. ${ }^{126}$ Third, the value of a call option increases as its exercise price decreases - the less you have to pay at stage two when you exercise the option, the more valuable the option to collect it will be (again, holding other variables equal). Finally, the value of a call option increases in both the time to maturity and the rate of interest. $^{127}$

In applying these gradients to the Sub-S Shelter, first, the option's value to the entrepreneur will be increasing in the present value of the tax savings from the shelter (the underlying asset). Second, because the present value of the tax savings from the shelter are determined by the entrepreneur's expected earnings from the business, the value of the option will also be increasing in the expected volatility of the entrepreneur's earnings from the business, provided that such income exceeds the threshold of "reasonable compensation." Third, the option's value will be decreasing in the Sub-S Shelter's exercise price (i.e., the bifurcation costs).

Entrepreneurs who perceive that the Sub-S Shelter call option has high value will, in expectation, be more likely to purchase the option at stage one by forming an S Corporation. There are good reasons to think that entrylevel entrepreneurs will place high value on the call option, and thus will be more likely to purchase it. First, as shown above, one of the determinants of

${ }^{125}$ See BREALEY ET AL., supra note 120, at 576-80.

${ }^{126} I d$. at $579-80$. The intuition is that increased volatility of an underlying asset generates bigger upside, as well as downside, returns. But a call option protects the holder from the downside, because the holder will simply decline to exercise the option if the value of the underlying asset is less than the strike price.

${ }^{127} \mathrm{Id}$. at $577-78$. The intuition is that someone who is acquiring an asset by way of a call option is essentially buying on credit - paying the exercise price now for the right to buy the stock later. This delay in payment is an interest-free loan from the option seller to the option buyer.

Pitt Tax Review | ISSN 1932-1821 (print) 1932-1996 (online) DOI 10.5195/taxreview.2013.16 | http://taxreview.law.pitt.edu 
the hypersalience of the shelter for entry-level entrepreneurs is the higher expected (present discounted) value of the shelter's tax savings as a proportion of total earnings. This translates into a higher underlying asset value of the Sub-S Shelter call option. In addition, by dint of their lack of experience in launching a business, entry-level entrepreneurs may have higher expected volatility of earnings. Higher earnings volatility of the business will mean higher volatility of the value of the underlying tax asset. Because the call option structure protects the holder against the downside of higher volatility (the holder has a right, but not an obligation, to exercise the option), this higher volatility implies higher overall Sub-S Shelter call option value for entry-level entrepreneurs. ${ }^{128}$ As a result, entry-level entrepreneurs should be more likely to purchase the Sub-S Shelter call option by forming an S Corporation. This moves outcomes away from the "neutral" entity choice that would be made by the entrepreneur in the absence of the Sub-S Shelter.

Thus, the Sub-S Shelter not only increases the deadweight losses associated with choosing a legal entity by increasing complexity and imposing higher deliberation costs on entry-level entrepreneurs, but it also distorts these entrepreneurs' entity decisions in a direction that may be costly for their businesses. This effect - behavioral distortion - is common to all (or at least most) tax shelters. ${ }^{129}$ But the particular costs of the distorted choices will vary across tax shelters. In the case of the Sub-S Shelter, where an entrepreneur chooses the S Corporation over the LLC, the key problem she faces is the risk that the opportunity costs of the $\mathrm{S}$ Corporation will outweigh its benefits-i.e., the entrepreneur will learn that she needs the flexibility of the LLC but will have sacrificed it to gain the nearer-term savings promised by the Sub-S Shelter. This situation, in which the entrepreneur "bets wrong," will result in a pure efficiency loss: the

\footnotetext{
${ }^{128}$ The possibility that the earnings volatility of entry-level entrepreneur will be high is separate from saying that their average earnings will be lower than those of non-entry-level entrepreneurs.

${ }^{129}$ See, e.g., Joseph Bankman, The Tax Shelter Problem, 57 NAT'L TAX J. 925 (2004); David A. Weisbach, Ten Truths about Tax Shelters, 55 TAX L. REV. 215, 222-25 (2002) (arguing that since there is no way to distinguish tax shelters from "legitimate" tax planning, one should be suspicious of all tax planning); George K. Yin, Getting Serious About Corporate Tax Shelters: Taking a Lesson from History, 54 SMU L. REV. 209 (2001).
}

Pitt Tax Review | ISSN 1932-1821 (print) 1932-1996 (online) DOI 10.5195/taxreview.2013.16 | http://taxreview.law.pitt.edu 
entrepreneur will have paid the purchase price of the option to pursue an outcome that is sub-optimal. ${ }^{130}$

The risk of "betting wrong" might play out in a number of ways. Suppose an entrepreneur purchases the Sub-S Shelter call option and forms the S Corporation at stage one, but discovers at stage two or later that her net returns from sheltering some of her business income from employment taxes are negative. For instance, she may not have much excess income to shelter in the early stages of her business and, at the same time, the $\mathrm{S}$ Corporation restrictions may hamper her ability to grow to scale by bringing in new investors, issuing a second class of stock, or other actions that would be precluded by the restrictions. Alternatively, she might find that her option is in the money for a few years, but then out of the money later on once she needs the flexibility of the LLC for growth. And, rather than just declining to exercise the Sub-S Shelter call option because it is out of the money, the entrepreneur may need to incur further costs of converting her entity from an S Corporation to the LLC. As seen in Part I of this Article, such a conversion is likely to generate tax liability if there are built-in gains in the S Corporation's assets, not to mention the other transaction costs of the conversion, such as legal advice. These distortions caused by the Sub-S Shelter will operate, on average, to limit the growth of entry-level entrepreneur's business - some businesses that "bet wrong" at stage one will not be able to surmount the challenges and costs of converting to an LLC, and their growth will be stunted or terminated entirely.

Is there empirical evidence that entry-level entrepreneurs are more likely to form S Corporations? The author's own observations as an attorney in a business law clinic confirm the widespread popularity among entry-level entrepreneurs of the S Corporation, there is limited evidence that $\mathrm{S}$ Corporations are popular with if not dominant among entry-level entrepreneurs. Walter Schwidetzky notes that S Corporations represent the largest share of returns among small and medium sized businesses, and attributes their popularity to the Sub-S Shelter. ${ }^{131}$ But figures on total

\footnotetext{
${ }^{130}$ This result stands in contrast to the financial options context where the option price accrues to a counter-party.

${ }^{131}$ See Schwidetzky, supra note 4, at 804-05 (citing statistics on types of entities filing tax returns in 1993, 1998, and 2003 tabulated by the staff of the Joint Committee on Taxation using
}

Pitt Tax Review | ISSN 1932-1821 (print) 1932-1996 (online) DOI 10.5195/taxreview.2013.16 | http://taxreview.law.pitt.edu 
annual filings of all entities in existence do not capture the popularity of the S Corporation relative to the LLC for entrepreneurs starting their businesses right now (as opposed to in the past). I leave exploring the empirics of what predicts the type of entity a given entrepreneur chooses to future work. There is evidence from the Kauffman Firm Survey that, among businesses with no employees and a low measure of assets (i.e., limiting the sample to "entry-level entrepreneurs") who do form a separate entity for the business, nearly 25 percent choose the S Corporation. ${ }^{132}$ Although it is unlikely that the universe of small and medium-sized businesses (defined as businesses with less than $\$ 1$ million in assets) overlaps perfectly with the universe of new businesses started by entry-level entrepreneurs, the figures broadly corroborate the idea that smaller, less sophisticated businesses may disproportionately gravitate towards the S Corporation. ${ }^{133}$

Part III of this Article explores potential solutions to the harms caused by the regressive hypersalience of the Sub-S Shelter for entry-level entrepreneurs.

\section{SALIENCE MANIPULATION IN FAVOR OF THE LLC AS A ROUTE TO REAL OPTION VALUE}

The preceding Part shows that the Sub-S Shelter is likely to be hypersalient for many entry-level entrepreneurs, and this hypersalience has regressive distributional effects as a matter of equity. What remedies might be available to improve the outlook for this cohort of entrepreneurs?

The most obvious solution to the Sub-S Shelter's regressive salience is to eliminate the shelter through sweeping reforms. ${ }^{134}$ For instance, Congress

Statistics of Income data, both, published and unpublished. Schwidetzky asks, "[t]o what is the S corporation popularity attributable? Taxpayers do not explain why they choose a particular entity when they file their tax returns, but the common belief is that $\mathrm{S}$ corporations continue to be popular because of the perceived opportunity they provide to reduce Social Security and Medicare taxes." Id. at 805.).

132 This is shown in my analysis of panel data that follows start-ups that commenced business in 2004 and continued to be in business through 2008. Data analysis was collaborated with the Ewing Marion Kauffman Foundation (results on file with author).

${ }^{133}$ See id. at $805-06$.

${ }^{134}$ One recently-suggested reform proposal from Walter Schwidetzky suggests that a broadened Subchapter K could subsume the role of Subchapter S, allowing it to be eliminated. See Schwidetzky, supra note 4, at 807-10 (advocating repeal of Subchapter S).

Pitt Tax Review | ISSN 1932-1821 (print) 1932-1996 (online) DOI 10.5195/taxreview.2013.16 | http://taxreview.law.pitt.edu 
could simply equalize the treatment of an entrepreneur's earnings, regardless of the type of entity through which they are generated. One could imagine extending the shelter to encompass non-compensation earnings generated by an LLC or other tax partnership, or changing the definition of NESE to include distributions or dividends from a corporation in which the owner is actively involved. Numerous commentators and advocacy groups have offered various proposals for how to shut down the shelter and achieve parity. ${ }^{135}$ Nonetheless, no solutions have garnered the requisite consensus or momentum. ${ }^{136}$ And the latest congressional proposal on small business tax reform, which does contemplate the repeal of both Subchapter K and Subchapter $\mathrm{S}$ in favor of a consolidated and streamlined pass-through regime for businesses, does not even attempt to tackle the employment tax dimension, listing it first among "unaddressed issues."137

Therefore, this Part seeks to sketch a narrowly-tailored approach to addressing the problem of the Sub-S Shelter's regressive salience. First, I observe that replacing the costly call option structure of the choice-of-entity decision with a structure that allows entrepreneurs to capture "real option value" can yield significant gains. Second, I suggest that such a restructuring can be achieved through government measures to adjust the salience of the Sub-S Shelter for entry-level entrepreneurs. By offering information about choice-of-entity that is targeted to the needs of entrylevel entrepreneurs, the salience of the Sub-S Shelter can be reduced at the same time that the advantages of the LLC can be emphasized. Such measures have the potential to neutralize - at low cost - the regressive hypersalience of the Sub-S Shelter for entry-level entrepreneurs.

\section{A. Choice-of-Entity as Real Option}

In Part II.B.2, option theory helped pinpoint the mechanism by which the Sub-S Shelter distorts the behavior of entry-level entrepreneurs.

${ }^{135}$ See Winchester, supra note 5, at 144-50.

${ }^{136} \mathrm{Id}$. at 145 .

${ }^{137} \mathrm{See}$ COMM. ON WAys AND MEANS, StRENGTHENING THE ECONOMY AND INCREASING WAGES by Making the TAX Code Simpler and Fairer for America's Small Businesses (2013), available at http://waysandmeans.house.gov/uploadedfiles/small_biz_summary_description_03_12_ 13 final.pdf.

Pitt Tax Review | ISSN 1932-1821 (print) 1932-1996 (online) DOI 10.5195/taxreview.2013.16 | http://taxreview.law.pitt.edu 
Because entry-level entrepreneurs are likely to place a higher value on the Sub-S Shelter call option than non-entry-level entrepreneurs, the call option structure of the choice has troubling efficiency and equity implications. However, thinking about choice of entity within an option framework can yield solutions to the status quo's regressive salience: I propose restructuring the choice-of-entity decision as a real option.

A real option, as opposed to a financial option, is an opportunity that exists in the "real world" to take an action-for example, the action could be a decision to seize (or to delay seizing) an investment opportunity, to enroll in (or drop out of) graduate school, to expand or curtail production in a factory, or other choices about committing resources to a project. ${ }^{138}$ In relation to the discussion of call options above, the distinguishing feature of a real option is that its option purchase price is zero. Thus, a free (or nearly free) real option does not require the buyer to forgo resources in order to preserve the option for future exercise. Some commentators discuss real options as "options that are given by nature" in that they are not being written by any particular counterparty. ${ }^{139}$

More specifically, two conditions are necessary for a given action with an uncertain outcome to have value as a real option. ${ }^{140}$ First, taking the action would result in a sunk cost - that is, taking the action ties up resources that cannot be recovered easily. Most prototypical real options, such as capital investments, are irreversible (or reversible only at great cost). Second, the action, with its attendant sunk costs, can be costlessly delayed, during which time the uncertainty surrounding the outcome of the action will resolve itself. Pursuant to these two conditions, the upshot of a real option is that allowing a decision-maker to remain uncommitted can create value, or at least avoid losses vis-à-vis a "regular" option that requires an up-front commitment in the form of the purchase price. Real options create value for their holders because they preserve the opportunity

\footnotetext{
${ }^{138}$ See Robert L. MCDonald, Derivatives MARKets 535 (2003).

${ }^{139}$ See Mark Klock, Financial Options, Real Options and Legal Options: Opting to Exploit Ourselves and What We Can Do About It, 55 ALA. L. REV. 63, 71-75 (2003).

${ }^{140}$ See Robert S. Pindyck \& Ayinash K. Dixit, The Options Approach to Capital Investment, 73 HARV. BUS. REV. 105 (1995) (delineating these four conditions).
}

Pitt Tax Review | ISSN 1932-1821 (print) 1932-1996 (online) DOI 10.5195/taxreview.2013.16 | http://taxreview.law.pitt.edu 
to bet on an uncertain outcome until the uncertainty has decreased or has been eliminated, thereby improving the holder's odds of success.

It is quite clear that the status quo choice-of-entity problem- the SubS Shelter call option - is structured as a regular call option, not a real one. To be able to shelter earnings from employment taxes in the future, the entrepreneur must pay the Sub-S Shelter option purchase price, which is defined above as the net deliberation and formation costs involved in choosing an S Corporation. This purchase price is unlikely to be zero (or to be close to zero) for an entry-level entrepreneur who is learning about entity choice and the Sub-S Shelter for the first time. And we have seen that requiring the entrepreneur to commit to an entity at the very outset of her business's existence generates losses if the Sub-S Shelter option does not end up in the money.

Transforming the structure of the choice-of-entity decision from a call option into a real option would solve these problems. A real option structure would allow the entrepreneur to delay, and perhaps avoid entirely, her deliberations about which entity to form. If she were able to delay her commitment to the Sub-S Shelter until she becomes more certain about the factors that will determine its value for her, her deliberations will be less speculative and thus far less arduous. In essence, the delay would allow the entrepreneur to update her beliefs: she will know with greater certainty whether the net present value of the tax savings of the Sub-S Shelter will justify the opportunity costs of forgoing the LLC's flexibility. Consequently, a real option structure would provide protection for entrylevel entrepreneurs in all states of the world. It eliminates the downside for those who would have bet wrong in a call option structure, protecting those entrepreneurs who would have formed S Corporations at the outset, only to find that the opportunity costs outweighed the benefits. Additionally, it would not prevent those for whom the S Corporation turns out to be the "right" decision from taking advantage of the shelter once their uncertainty has abated. In sum, entry-level entrepreneurs would end up with lessdistorted choices and higher net utility. Moreover, the deliberation costs imposed by the shelter could be reduced.

\section{B. Restructuring the Sub-S Shelter Call Option as a Real Option}

How could the choice-of-entity decision be restructured as a real option without requiring significant, and likely controversial, changes in the tax law? To answer this question, I return to the two conditions for an

Pitt Tax Review | ISSN 1932-1821 (print) 1932-1996 (online) DOI 10.5195/taxreview.2013.16 | http://taxreview.law.pitt.edu 
action to be structured as a real option. First, the relevant action or commitment of resources must result in sunk costs. As expressed in this Article, the commitment to form an S Corporation does generally involve sunk costs. Any resources used to file the paperwork to form the corporation and pay filing fees are, obviously, sunk. But where there has been growth in the business, reversing course can be costly, as the conversion of an S Corporation to an LLC generally involves the recognition, for tax purposes, of any gains built into the assets of the corporation. The tax consequences of converting from an S Corporation to an LLC can also be considered sunk.

The second condition - that the commitment to form an S Corporation can be costlessly delayed-is tougher to meet. An entrepreneur could, at least theoretically, delay forming an entity of any type until some of her uncertainty about her business had been resolved. For instance, she could wait to see whether she would need the flexibility of the LLC to bring in new investors or to offer specialized types of equity, such as preferred shares. She could wait to see whether she would earn in excess of a reasonable salary. She could wait to see other key outcomes that would determine whether the Sub-S Shelter would deliver sufficient value to justify its opportunity cost. But operating as a sole proprietor or a general partnership, without the protection of limited liability that a separate entity offers, carries substantial risks. Additionally, the paperwork and related costs of transferring contracts and agreements of a going concern to the new entity once it is formed would likely be significant. Thus, proposing that entrepreneurs simply wait to form a separate entity until they had greater certainty about their business's future would not meet the second real option condition - the delay would be far from costless.

Instead, I propose taking measures to reduce the salience of the status quo Sub-S Shelter call option for entry-level entrepreneurs, while increasing the salience of the LLC as a real option. The proposal hinges on the observation that there are fewer sunk costs involved in choosing an LLC as compared to an S Corporation. Indeed, one of the key selling points of the LLC is its ease of conversion - switching from being organized as an LLC into a corporation (including an S Corporation) is far less likely to trigger adverse tax consequences than the reverse maneuver. This suggests a strategy that could dominate the status quo for cost-sensitive, entry-level entrepreneurs. An entrepreneur who seeks the limited liability protection of a separate entity could form an LLC at stage one and then, once she has resolved some of her uncertainty about her business's trajectory, she could

Pitt Tax Review | ISSN 1932-1821 (print) 1932-1996 (online) DOI 10.5195/taxreview.2013.16 | http://taxreview.law.pitt.edu 
revisit the question at stage two the question of whether the potential employment tax savings from the Sub-S Shelter are sufficiently compelling in light of the S Corporation's restrictions. This approach would leave the existing list of choices facing entrepreneurs exactly the same; thus, it would require no overhaul of the Code or complicated legislative negotiations. Additionally, no entrepreneur would be forced or mandated to form one type of entity over another. Rather than seeking to steer entry-level entrepreneurs to always choose the LLC over the S Corporation, the goal would be to neutralize the regressive salience of the Sub-S Shelter by bolstering the salience of the LLC-as-real-option. The LLC would not be mandatory, but it could be recast as an attractive real option by manipulating the salience of its benefits for entry-level entrepreneurs.

The advantages of this approach are quite powerful. First, reducing the salience of the Sub-S Shelter for entry-level entrepreneurs would curtail the deliberation costs imposed by the status quo - as seen in Part I of this Article, the salience of the Sub-S Shelter is a key complicating factor because it offers near-in-time tax savings that often seem more valuable than the flexibility of the LLC, which would likely only matter farther in the future. Making the choice-of-entity process easier to navigate in this fashion would result in welfare gains for entry-level entrepreneurs. And it might even spur more new businesses to get started because, at least on the margin, choice-of-entity would become a less significant roadblock.

Second, recasting the LLC as a salient real option will compound this effect of decreasing deliberation costs - the savings from the Sub-S Shelter will appear less compelling, but the advantages of forming an LLC at time one will appear more compelling. This can be accomplished by highlighting how the LLC provides protection against the situation in which the entrepreneur "bets wrong"- she forms an S Corporation but then finds out that she needs the flexibility of a limited liability company. In a sense, the LLC-as-real-option can be presented to the entrepreneur as an insurance policy: the "premiums" that she pays for the protection are the forgone employment tax savings that she might have realized had she decided to form an S Corporation at the outset. And, of course, the entrepreneur can always choose to "drop" the insurance, and convert to an S Corporation, when her uncertainty about the value of the Sub-S Shelter decreases.

Decreasing the salience of the Sub-S Shelter while increasing the salience of the LLC as a real option can be accomplished in any number of ways. The common denominator is the government's use of tools to manipulate salience to "nudge," in a targeted fashion, entry-level

Pitt Tax Review | ISSN 1932-1821 (print) 1932-1996 (online) DOI 10.5195/taxreview.2013.16 | http://taxreview.law.pitt.edu 
entrepreneurs towards the LLC and away from the Sub-S Shelter. ${ }^{141}$ As Cass Sunstein and Richard Thaler state in their popular book about behavioral law and economics, "salience can be manipulated, and good choice architects can take steps to direct people's attention to incentives."142 Additionally, Susan Cleary Morse makes a strong case for using salience as a tool to motivate tax compliance among groups that historically have had high levels of under or non-reporting (note that entry-level entrepreneurs, who may operate partially in the cash economy, are likely to be a part of these groups). ${ }^{143}$ I piggyback on this intuition of salience manipulation to list three ways in which the salience of the Sub-S Shelter, versus the LLC, can be adjusted to nudge entry-level entrepreneurs towards better outcomes.

First, simply providing - through channels that entry-level entrepreneurs already access - choice-of-entity information that highlights the drawbacks of the Sub-S Shelter while highlighting the advantages of the LLC-as-real-option would be a step in the right direction. As it stands, information about how to choose an entity is hard to come by-because there are so many factors at play under current law, the refrain commonly heard is "you should talk to a lawyer." While engaging a lawyer may be helpful in terms of distilling the pros and cons of the choice between or among entities, it is undeniably costly. Further, this means that the lawyer must stand in the shoes of the entry-level entrepreneur, so the entrepreneur's deliberations may be circumscribed, but they are unlikely to be eliminated. Thus, where the government seeks to decrease the salience of the Sub-S Shelter while increasing the salience of the LLC, it should consider offering choice-of-entity advice aimed directly at the cohort of entry-level entrepreneurs. According to Morse, "taxpayers give more attention and focus to more salient IRS communications."

\footnotetext{
${ }^{141}$ The use of the term "nudge" is in reference to the popular book by Cass Sunstein and Richard Thaler. It reviews the behavioral economics (and law) literature on how the presentation of choices, and the incentives that drive those choices, can affect outcomes. Salience is one of their topics. See THALER $\&$ SUNSTEIN, supra note 15 , at 98-99.

${ }^{142}$ Id. at 99.

${ }^{143}$ See Morse, supra note 18 , at 500-03.

${ }^{144}$ Id. at 500 .
}

Pitt Tax Review | ISSN 1932-1821 (print) 1932-1996 (online) DOI 10.5195/taxreview.2013.16 | http://taxreview.law.pitt.edu 
Such communications, and the information they contain, must be tailored to the needs, and abilities to process tax-related information, of entry-level entrepreneurs. The information could be offered in a variety of ways, and the government could experiment to see which are most effective in reducing the salience of the Sub-S Shelter while increasing the salience of the LLC. For instance, the IRS might offer a publication discussing choice-of-entity for entry-level taxpayers in particular. No such publication currently exists. By acknowledging the cash constraints endemic to this group, as well as their high levels of uncertainty about their businesses' prospects, such a targeted publication could do a better job of influencing entry-level entrepreneurs than a more general publication. In addition, the IRS could highlight in the publication the very real risks of relying on the Sub-S Shelter: it does not have a guaranteed existence, and it could attract more intense scrutiny as the audit priorities of the IRS change. Generally, the IRS can experiment with different ways to provide this targeted information. Morse discusses, in particular, the use of simple slogans, testimonials from individuals easily identifiable as self-employed, and the use of video and other media in addition to text as being promising techniques. ${ }^{145}$ The explosion in social media provides additional possibilities: the IRS now has a presence on Twitter, Tumblr, Facebook and other new media platforms. ${ }^{146}$

Second, the IRS could experiment with providing information for entry-level entrepreneurs via its partners, such as local business planning groups and chapters of the Small Business Administration, to emphasize the benefits of choosing an LLC as a business vehicle.

Third, the IRS could reach out to individual states - the level at which individuals actually form their entities - to help tailor choice-of-entity information on their websites or in their state-level publications for entrylevel entrepreneurs. Because each of these salience-manipulation strategies is fairly low-cost and non-exclusive in scope, a variety of approaches could be explored and the results studied to gauge how well each works from a

${ }^{145}$ Id. 504-07 (noting that simpler messages have more salience; it "could grab the taxpayer's attention and cue the decision process ...." Id. at 504.).

${ }^{146}$ One can connect with the IRS on Facebook, Tumblr, YouTube, via podcasts and on mobile devices using IRS2Go apps. The IRS Twitter handle is @IRSnews or, for tax professionals, @IRStaxpros. See IRS New Media, IRS.GOv, http://www.irs.gov/uac/IRS-New-Media-1.

Pitt Tax Review | ISSN 1932-1821 (print) 1932-1996 (online) DOI 10.5195/taxreview.2013.16 | http://taxreview.law.pitt.edu 
taxpayer behavioral perspective among entry-level entrepreneurs to reduce the hypersalience of the Sub-S Shelter while increasing the salience of the LLC.

There are certainly drawbacks to this quasi-real option structure. First, it imposes an extra set of transaction costs on those entrepreneurs who decide to "drop" the insurance policy of the LLC and convert to the S Corporation at stage two, once their uncertainty has resolved. For those entrepreneurs who conclude that they should form an S Corporation in order to benefit from the Sub-S Shelter, the conversion at stage two will entail additional costs: fees to establish the new corporation will be due, and the transaction will almost certainly require the services of a lawyer to ensure that the distribution of the assets of the LLC to the members and the re-contribution of those assets to the corporation happens in the right way. ${ }^{147}$ If these transaction costs at stage two outweigh the deliberation costs at stage one that the entrepreneur avoided by forming the LLC under the quasi-real option structure, a risk-neutral agent will be worse off than under the status quo. But if it is assumed that most entry-level entrepreneurs are risk-averse when it comes to tax-related gambles (as opposed to business decisions), the quasi-real option LLC strategy has the potential to improve options.

Second, an entry-level entrepreneur's uncertainty about whether or not to use the Sub-S Shelter may not resolve itself promptly, in one fell swoop, or in a fully consistent manner. These possibilities would likely complicate the entrepreneur's decision about whether to convert from the LLC to an S Corporation. Indeed, the entrepreneur who has pursued the quasi-real option LLC strategy at time one may, depending on how her business grows, simply be delaying her deliberations about whether the Sub-S Shelter will benefit her. If this is the case, forming the LLC as a quasi real option still works because it allows some of the entrepreneur's uncertainty to be resolved, but the deliberation cost savings will not be as substantial.

${ }^{147}$ See supra Part III.B.2.

Pitt Tax Review | ISSN 1932-1821 (print) 1932-1996 (online) DOI 10.5195/taxreview.2013.16 | http://taxreview.law.pitt.edu 


\section{CONCLUSION}

I seek to make two contributions through this Article, which relate to the well-recited problem of the Sub-S Shelter's role in choice-of-entity. First, the Sub-S Shelter is problematic not only because it results in inequitable outcomes across high-earning professional taxpayers and substantial revenue losses to the government, but also because it is disproportionately costly for entry-level entrepreneurs. The presence of the shelter complicates decision-making about choice-of-entity for these entrepreneurs and distorts their choices about the appropriate entity. On nearly all dimensions other than employment taxes, the LLC provides longterm ownership and capital structure flexibility with which the $\mathrm{S}$ Corporation cannot compete. But for cash-constrained new businesses, there may be a temptation to organize as an S Corporation to facilitate lower employment tax liabilities in the near term while hoping that the $\mathrm{S}$ Corporation constraints will not be binding in the longer term. It is anyone's guess how many S Corporations bump up against the constraints and are forced to engage in costly remedial measures such as converting to a different entity or, worse, going out of business because they cannot afford to adapt.

Second, the source of these costs is the regressive hypersalience of the Sub-S Shelter for entry-level entrepreneurs. Because entry-level entrepreneurs are likely to earn less from their businesses, face higher personal discount rates due to their resource constraints, and be optimistic about how quickly their business will generate earnings in excess of a reasonable salary, the Sub-S Shelter is hypersalient for entry-level entrepreneurs as compared to better-resourced entrepreneurs. Accordingly, I argue that providing targeted information about choice-of-entity to entrylevel entrepreneurs can dampen the hypersalience of the Sub-S Shelter while increasing the salience of the LLC. Such targeted information can improve efficiency by reducing entry-level entrepreneurs' deliberation costs, neutralizing distortions, and unlocking real option value.

Pitt Tax Review | ISSN 1932-1821 (print) 1932-1996 (online) DOI 10.5195/taxreview.2013.16 | http://taxreview.law.pitt.edu 